\title{
Diamond Electrochemistry at the Nanoscale: A Review
}

\author{
Nianjun Yang, ${ }^{\dagger, *}$ John S. Foord,, ${ }^{\ddagger}$ Xin Jiang ${ }^{\dagger, *}$ \\ ${ }^{\dagger}$ Institute of Materials Engineering, University of Siegen, Siegen 57076, Germany \\ ${ }^{\ddagger}$ Chemistry Research Laboratory, University of Oxford, Mansfield Road, Oxford, OX1 3TA, \\ UK
}

\begin{abstract}
Words)
Diamond electrochemistry using planar macroscopic diamond films has been widely investigated. Due to the non-uniform doping in diamond, boundary effects, and the varied ratios of graphite to diamond, such systems only provide averaged electrochemical signals over the full electrode. To clarify electrical and electrochemical properties of diamond at the nanoscale, the use of diamond nanostructures (e.g., nanotextures, nanowires, networks, nanoelectrodes, etc.) and particles (e.g., undoped nanoparticles, boron-doped particles), is highly important. In this paper, recent progress and achievements concerning diamond nanoelectrochemistry are considered. After a brief introduction of synthetic strategies to form diamond nanostructures and particles, their electrochemical properties in the presence and absence of redox probes are shown, followed by their use in electroanalysis (e.g., electrochemical, biochemical sensing, etc), electrochemical energy storage (e.g., electrochemical capacitors, batteries, etc.), electrocatalysis, and related applications. Topical problems and the future of diamond nanoelectrochemistry are discussed.
\end{abstract}

Keywords: Diamond, Nanoelectrochemistry, Nanostructures, Particles, Electrochemical applications

*Corresponding author. Tel: 49 2717402531. E-mail: nianjun.yang@uni-siegen.de (Nianjun Yang).

*Corresponding author. Tel: +44 1865 275967E-mail: john.foord@chem.ox.ac.uk (John S. Foord).

*Corresponding author. Tel: 49 2717402966. E-mail: xin.jiang@uni-siegen.de (Xin Jiang) 
Table of Content
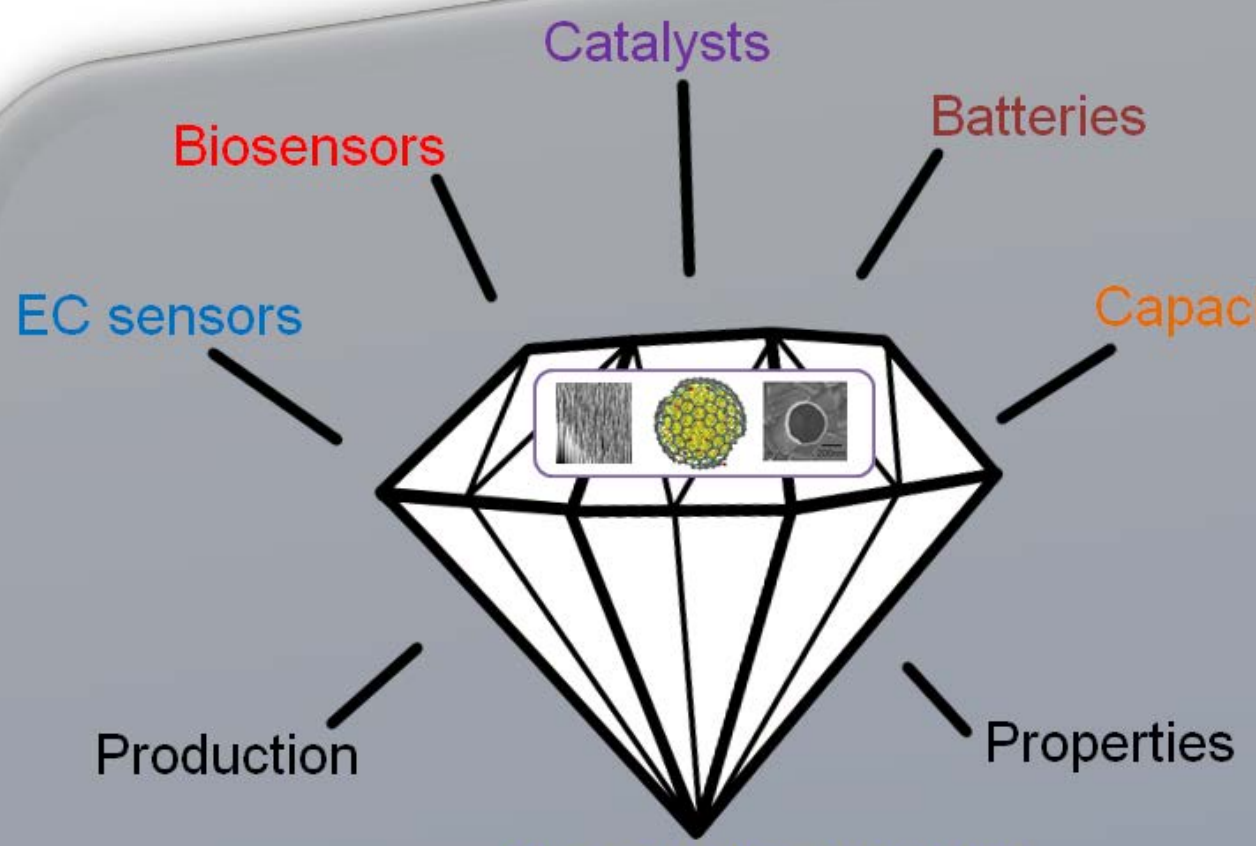

Nanoelectrochemistry 


\section{Outline of TOC}

\section{Introduction}

2. Synthetic strategies of diamond nanostructures and particles

2.1 Formation of diamond nanostructures

2.2 Fabrication of diamond nanoelectrodes

2.3 Production of diamond particles

2.3.1 Un-doped diamond nanoparticles

2.3.2 Doped-diamond particles

\section{Electrochemical properties of diamond nanostructures and particles}

3.1 Interfacial properties of diamond nanostructures

3.2 Voltammetry on diamond nanoelectrodes

3.3 Electrochemical activity of diamond particles

3.3.1 Un-doped diamond nanoparticles

3.3.1.1 Detonation diamond nanoparticles

3.3.1.2 HPHT diamond nanoparticles

3.3.2 Doped diamond particles

4. Electrochemical applications of diamond nanostructures and particles

4.1 Electroanalysis

4.1.1 Diamond nanostructures

4.1.2 Diamond nanoparticles

4.2 Electrochemical energy storage

4.2.1 Electrochemical capacitors

4.2.1.1 Diamond nanostructures

4.2.1.2 Diamond nanoparticles

4.2.2 Other energy storage devices

4.3 Electrocatalysts

4.3.1 Diamond nanostructures

4.3.2 Diamond particles

4.4 Other applications

\section{Summary and outlook}

\section{Acknowledgements}

\section{References}




\section{Introduction}

Iwaki et al. in 1983 [1] and later Pleskov et al. in 1987 [2] introduced diamond as an electrode material. The subsequent development of highly effective methods for diamond growth on conductive substrates at sub-atmospheric, rather than ultra-high-pressure-high-temperature (HPHT), accelerated the development of diamond based electrode materials. Through doping with acceptor-type impurity (e.g., boron) during the chemical vapor deposition (CVD) growth, diamond film can be semi-conductive ( $p$-type), semi-metallic, or superconductive [3-5]. The marriage of conductive diamond and electrochemistry then opened a new field in semiconductor electrochemistry, namely diamond electrochemistry [6-8].

Heavily boron-doped, conductive diamond has many unique features over metal and other carbon electrodes [3-12]. For example, diamond has a low and stable capacitive current in both aqueous and non-aqueous solutions. For a nanocrystalline diamond electrode with a boron-doping level of $5 \times 10^{20} \mathrm{~cm}^{-3}$, its double-layer capacitance is about 3.6-7, 14-20 and 11$15 \mu \mathrm{F} \mathrm{cm}^{-2}$ in aqueous, organic, and ionic liquid solution, respectively. The oxidized diamond electrode has a bigger capacitive current than a hydrogen-terminated one. A diamond electrode has a wide electrochemical potential window. Depending on the threshold of the current density used, the value of this window might be different. For a heavily boron-doped single crystalline diamond sample with the boron concentration of $5 \times 10^{20} \mathrm{~cm}^{-3}$, the potential window is about $3.2 \mathrm{~V}$ in aqueous solutions, $4.6 \mathrm{~V}$ in organic solutions, and $4.9 \mathrm{~V}$ at room temperature ionic liquid, if the window is defined as the range between the potentials where the anodic and cathodic current densities reach $1.0 \mathrm{~mA} \mathrm{~cm}{ }^{-2}$. Diamond surfaces can be terminated with hydrogen, hydroxyl, and oxygen using approaches such as plasma and electrochemical treatments. These different surface terminations lead to its controllable surface wettablity (hydrophilic, hydrophobic surface). In other words, the electronic properties of the diamond/electrolyte interface is tunable with respect to energy alignments of interacting levels. These surfaces can be characterized using surface-sensitive redox probes (e.g., $\left.\mathrm{Fe}(\mathrm{CN})_{6}^{3-/ 4-}\right)$. From voltammetry the redox peak currents and potential separation of anodic and cathodic waves as well as the electron transfer resistance from impedance give more details of these surfaces. With regard to these surface terminations, diamond can be functionalized with different linkers with chemical, photochemical, electrochemical, and thermal approaches. Moreover, weak or no surface bio-fouling has been seen on diamond surface. Diamond is biocompatible and has rich surface chemistry. Various analytes (e.g. biomolecules) can be immobilized and detected on such interfaces. Furthermore, diamond 
shows high chemical stability in harsh environments (e.g., acidic and alkaline solutions, etc.) and/or at high voltage and current densities. Diamond is ultra-hard (50-150 GaP) and thus various diamond nanostructures (e.g. nanotextures, nanowires, networks, nanoparticles can be designed and produced. Although these features vary with the nature of diamond, borondoping level, ratio of graphite to diamond, surface morphology, surface terminations and the electrolyte used, heavily boron-doped, conductive diamond is still recognized as one of the best electrodes.

Many successful reports have been presented about the use of planar macroscopic diamond electrodes for fundamental electrochemistry, bio electrochemistry, electroanalysis, electrosynthesis, electrocatalysis, photoelectrocatalysis, and environment (e.g., electrocatalytic degradation of pollutants and/or wastewater treatment, etc.) and related applications [3-24]. In these studies most of results were based only on averaged electrochemical signals detected over the full electrode. To detect electrical and electrochemical properties of diamond electrodes locally or to figure out the property difference of macroscopic bulk diamond electrodes from their nanoscale structures, the investigation of diamond electrochemistry at the nanoscale by use of diamond nanostructures and nanoparticles, namely, diamond nanoelectrochemistry is strongly needed. In this way, the effect of morphology (e.g., sizes, shapes, and length), composition (e.g., the ratio of graphite to diamond), non-uniform doping in diamond, boundary effects, and surface terminations/functionalization of diamond nanostructures and particles on their electrochemical properties can be clarified. These studies will play a significant role in widening the applications of macroscopic and nanoscale diamond for electroanalysis (e.g., electrochemical sensor development), electrochemical energy storage, electrocatalysis, and related scientific fields.

We therefore summarize in this paper recent progress and achievements about diamond electrochemistry at the nanoscale by use of diamond nanostructures (e.g., nanotextures, nanowires, porous diamond, etc.) [25-77], diamond particles (e.g., un-doped and doped particles, etc.) [78-153], and diamond nanoelectrodes [154,155]. The applications of these nanostructures and particles in the fields of electroanalysis (e.g., electrochemical, biochemical sensors, etc.), electrochemical energy storage (e.g., supercapacitors, lithium batteries, etc.), electrocatalysis, and other related aspects are shown. Diamond nanoelectrode array (NEA) and nanoelectrodes ensemble (NEE) are introduced as promising tools for the detection of 
surface-sensitive adsorption at the nanoscale. After showing the published results in the literature, we close this review with a summary and outlook about the future trends in diamond electrochemistry at the nanoscale by use of diamond nanostructures and particles.

\section{Synthetic strategies of diamond nanostructures and particles}

\subsection{Formation of diamond nanostructures}

Diamond nanostructures, including nanotexture (also called nanograss, nanowinkles, nanocone, etc.) with dimensions of typically a few nanometers, nanowires (also called nanoneedles, nanorods, nanoforests, etc.) with lengths from hundreds of nanometers to a few micrometers, and networks (also called foam, porous film, etc.) with pore sizes from few nanometers to micrometers have been fabricated and employed as the working electrodes for electrochemistry and related electrochemical applications. Figure 1 shows some example images of these nanostructures. They have been fabricated using a top-down, bottom-up, template-free, or related techniques.
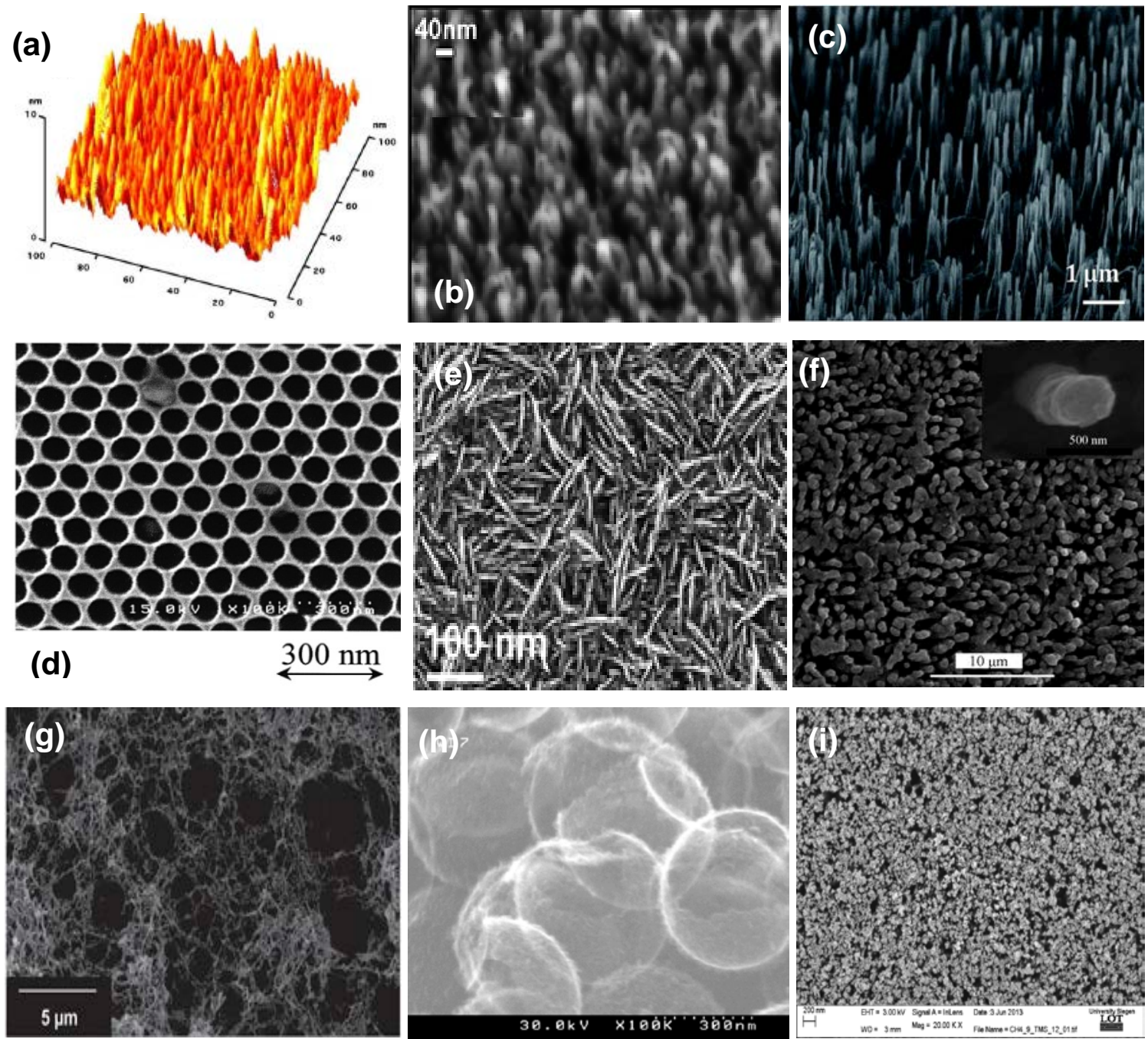
Figure 1. AFM (a) and SEM (b-i) images of diamond nanotextures. (a) nanotextures fabricated via a top-down etching of diamond in an oxygen/tetrafluoromethane gas mixture through a hard mask from diamond nanoparticles (Reproduced with permission from Ref. [29] Copyright 2008, ACS Publisher), (b) nanograss fabricated via oxygen plasma etching of diamond without any mask (Reproduced with permission from Ref. [32], Published by The Royal Society of Chemistry), (c) nanowires fabricated via oxygen plasma etching of diamond trough a mask from $\mathrm{SiO}_{2}$ (Reproduced with permission from Ref. [53], Published by The Royal Society of Chemistry), (d) nanoporous honeycomb diamond fabricated via oxygen plasma etching of diamond through an anodic alumina mask (Reproduced with permission from Ref. [61] Copyright 2001, Elsevier), (e) nanowires overgrown on nucleation sites of diamond nanoparticles and titanium powder (Reproduced with permission from Ref. [33], Published by The Royal Society of Chemistry), (f) nanorod forest fabricated via a bottom-up overgrowth of silicon nanowires with diamond films (Reproduced with permission from Ref. [34] Copyright 2009, ACS Publisher), (g) nanowires fabricated via a bottom-up overgrowth of carbon nanotubes with diamond films (Reproduced with permission from Ref. [152] Copyright 2014, Nature Publisher), (h) diamond foam fabricated via overgrowth of $\mathrm{SiO}_{2}$ spheres with diamond films (Reproduced with permission from Ref. [74] Copyright 2013, Elsevier), (i) diamond network fabricated via selective wet-chemical removal of cubic SiC from diamond/SiC composited films (Reproduced with permission from Ref. [64] Copyright 2015, ACS Publisher).

In a top-down approach, diamond is etched away with reactive ions through an etching (hard) mask. The applied gases include oxygen, hydrogen/argon, and oxygen/tetrafluoromethane. The morphology (e.g., size, length, density, etc.) of as-prepared nanostructures is determined mainly by the etching mask (e.g., nature, size, shape, etc.) and etching conditions (e.g., temperature, gas atmosphere, pressure, time, etc.). Various mask materials (e.g., $\mathrm{Al}, \mathrm{SiO}_{2}, \mathrm{Au}$, $\mathrm{Ni}$, Mo, polymers, oxides, nitrides, and diamond nanoparticles, etc.) have been applied [2628]. For example, the etching mask of 5-10 nm diamond nanoparticles was applied to form diamond nanotextures [29]. With an etching time of $10 \mathrm{~s}$ in a gas mixture of oxygen (97\%) and tetrafluoromethane (3\%), the nanotextures (1 - $5 \mathrm{~nm}$ in diameters, $11 \mathrm{~nm}$ in distance) were produced [29]. If nickel nanoparticles were used as the etching mask, the formed diamond nanowires have the diameter of $(23 \pm 7) \mathrm{nm}$, length of $1200( \pm 200) \mathrm{nm}$, and a density of about $10^{11} \mathrm{~cm}^{-2}$ when an etching time of $5 \mathrm{~min}$ and an oxygen inductive coupled plasma were applied [30]. When $\mathrm{SiO}_{2}$ etching mask and an oxygen inductive coupled plasma were 
employed, a short etching time (e.g., $40 \mathrm{~min}$ ) led to the fabrication of so-named short nanowires (e.g., with a length of $1.0 \pm 0.3 \mu \mathrm{m}$, a tip radius of $50 \pm 10 \mathrm{~nm}$, a base radius of $200 \pm$ $50 \mathrm{~nm}$, an average spacing of 8-100 nm, and a density of $(5 \pm 3) \times 10^{8} \mathrm{~cm}^{-2}$ ), while a long etching time (e.g., $108 \mathrm{~min}$ ) got long nanowires (e.g., with a length of $3 \pm 0.2 \mu \mathrm{m}$, tip diameter of $10-50 \mathrm{~nm}$, and a density of $\left.(15 \pm 3) \times 10^{8} \mathrm{~cm}^{-2}\right)$ [35,53].

In a bottom-up approach, diamond nanostructures are produced by the overgrowth of the template from other nanostructures (e.g., diamond nanoparticles, silicon nanowires, carbon nanotubes, $\mathrm{SiO}_{2}$ spheres, polymer, etc.) with diamond films using a CVD method. Up to the morphology of the templates, various diamond nanostructures (e.g., vertically aligned wires, diamond foams, porous membranes, etc.,) have been formed. For example, diamond nanowires have been grown on nucleation sites of diamond nanoparticles $(\sim 5.0 \mathrm{~nm}$ in diameter $)$ and titanium powder ( 37.0 mesh) using a microwave plasma enhanced CVD method (MPCVD). These nanowires possessed a characteristic 'acicular' like structure in a few nanometers' width. The nanowires grown at $700{ }^{\circ} \mathrm{C}$ showed higher electrical conductivity than those grown at other temperatures [33]. Other reported nanostructures are diamond nanowires produced by overgrowth of silicon nanowires [65] and carbon nanotubes [152], diamond foam or porous diamond electrodes fabricated by overgrowth of $\mathrm{SiO}_{2}$ spheres [61,62], highly porous polypyrrole scaffold [73], and carbon nanotubes [71].

The template-free and related techniques have been employed as well to form diamond nanostructures [32,64,71]. For example, selective wet-chemical removal of cubic SiC from diamond/SiC composite film led to the generation of a porous diamond network with threedimensionally interconnected pores [64]. Determined by the ratio of the cubic SiC phase in the composite films, the porosity of these networks was tuned from 15 to $68 \%$ and the sizes of pores varied from ten of nanometers to few micrometers. A two-step thermal treatment method was applied to produce porous conductive boron-doped diamond film. The sizes of pores were changed from tens to several hundred nanometers [72].

\subsection{Fabrication of diamond nanoelectrodes}

Diamond NEA and NEE have been fabricated using E-beam lithography and nanosphere lithography, respectively [154]. In the NEA, the nanoelectrodes with a well-defined radius of $250 \mathrm{~nm}$ and electrode density of $11 \times 10^{5} \mathrm{~cm}^{-2}$ are distributed in a hexagonal order and a 
distance of $10 \mu \mathrm{m}$ next to another nanoelectrodes [154]. For the NEE, the density and the average distance of the nanoelectrodes are dependent on the concentration of $\mathrm{SiO}_{2}$ solution used. For example, by use of a $\mathrm{SiO}_{2}$ concentration of $9.55 \times 10^{8} \mathrm{~cm}^{-3}$, one can have a NEE with a size of about $175 \mathrm{~nm}$, electrode density of $9.7 \times 10^{5} \mathrm{~cm}^{-2}$, and an average distance of $\sim 10 \mu \mathrm{m}$ next to neighboring nanoelectrodes [154].
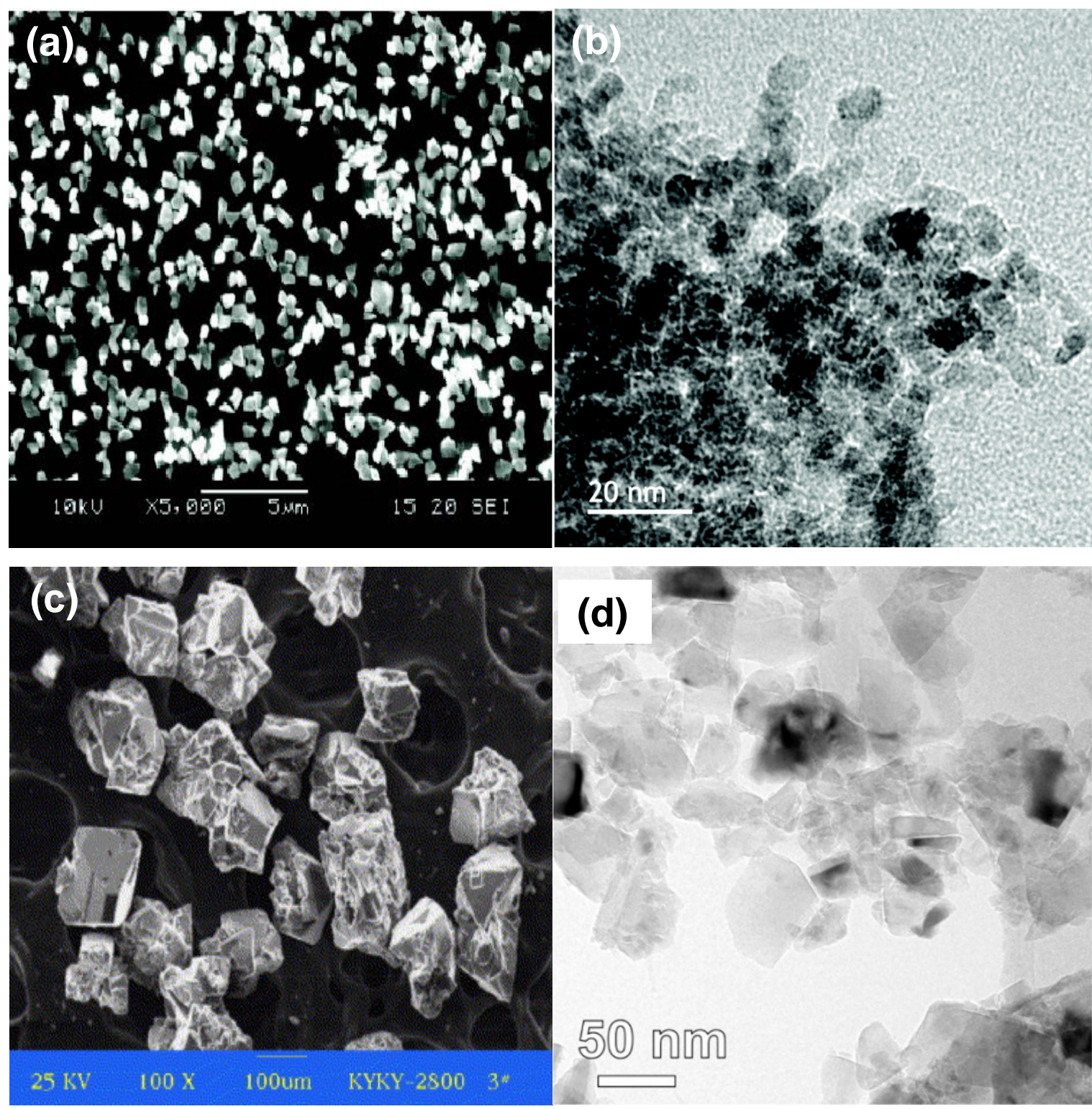

Figure 2 TEM (a,d) and SEM (b,c) images of diamond particles. (a) detonation diamond nanoparticles (10 $\mathrm{nm}$ in diameter) (Reproduced with permission from Ref. [83] Copyright 2009, ACS Publisher), (b) two-dimensional assemblies of diamond particles (Reproduced with permission from Ref. [91] Copyright 2011, ACS Publisher), boron-doped diamond particles (Reproduced with permission from Ref. [145] Copyright 2007, Elsevier), (d) boron- 
diamond nanoparticles (about 30 to $70 \mathrm{~nm}$ in diameter) (Reproduced with permission from Ref. [147] Copyright 2014, ACS Publisher).

\subsection{Production of diamond particles}

\subsubsection{Un-doped diamond nanoparticles}

Un-doped diamond nanoparticles with size down to $20 \mathrm{~nm}$ have been produced via ball milling of micrometer sized HPHT diamond films. However, in this way, diamond nanoparticles less than $10 \mathrm{~nm}$ were seldom obtained. With the aid of bead assisted sonic disintegration, the production of diamond nanoparticles (e.g., 70-80 nm in diameter) was realized by milling polycrystalline CVD diamond films. These nanoparticles have faceted shapes with sharp edges, which correspond to fractured crystallographic planes. Using such a method, few spherical nanoparticles were found. Another more widely applied approach to produce spherical diamond nanoparticles these days is to use dynamic processes from molecules of explosives and different graphite precursors [5,78], including direct transformation of graphite by an external shock wave, the detonation of graphite mixed with explosive, and the detonation of high energy explosive. Detonation diamond nanoparticles have a core of $\mathrm{sp}^{3}$ diamond with a size of $4-5 \mathrm{~nm}$ and a shell of a mixture of $\mathrm{sp}^{2}$ and $\mathrm{sp}^{3}$ carbon as well as oxygen based functional groups (i.e. carboxylic acids, esters, lactones) [5,78]. Figure 2 shows some example SEM and TEM images of these diamond nanoparticles.

\subsubsection{Doped-diamond particles}

Doped-diamond particles, mainly boron-doped diamond particles, have been obtained via the overgrowth of insulating diamond particles with boron-doped diamond, solid-state diffusion, and milling of boron-doped diamond films [143,144]. For example, boron-doped diamond powder was synthesized under HPHT using B-doped graphite intercalation compositions as carbon sources [145]. Recently, Kruger et al. [147] produce 10-60 nm boron-doped diamond nanoparticles by use of heavily boron-doped diamond films as the starting material and a multistep milling process, followed by purification and surface oxidation.

\section{Electrochemical properties of diamond nanostructures and particles}

\subsection{Interfacial properties of diamond nanostructures}

Voltammetry and impedance were applied to characterize the interfacial properties (e.g., real electrode areas, their electrochemical activities, etc.) of diamond nanotextures and nanowires 
[29-31]. The analysis of Mott-Schottky plots in the absence of redox probes [29] as well as the analysis of electrochemical impedance spectra using an electric equivalent circuit and the cyclic voltammograms in the presence of redox probes $\left(\left[\mathrm{Fe}(\mathrm{CN})_{6}\right]^{3-/ 4-}\right)[31]$ were conducted. For example, the built-in potential of diamond nanotextures (1 - $5 \mathrm{~nm}$ in diameters, $11 \mathrm{~nm}$ in distance) was 1.6 V. It was calculated from the Mott-Schottky plots of both a smooth diamond electrode and diamond nanotextures recorded in $0.1 \mathrm{M} \mathrm{pH} 7.4$ phosphate buffer at a fixed frequency of $1.0 \mathrm{kHz}$. The estimated surface area of diamond nanotextures was 2.1 times higher than that for a smooth diamond [29]. From the capacitive currents in $0.1 \mathrm{M} \mathrm{KCl}$, the surface area of diamond nanowires (with diameters of $35 \pm 5 \mathrm{~nm}$, lengthes of $1200 \pm 200 \mathrm{~nm}$, and the density of $\sim 10^{10} \mathrm{~cm}^{-2}$ ) was estimated. It was about 10 times higher than that for a smooth diamond electrode [30]. However, the electrode active area of diamond nanowires was only 1.5 times larger than that of a smooth diamond, calculated from a quasi-reversible and diffusion-controlled electrode reaction of $\mathrm{Fe}(\mathrm{CN}) 6^{3-/ 4-}$ on such an electrode [30]. Similar result, namely the electrode area calculated from the capacitive current is much larger than that obtained from the faradaic current of redox probes, was noticed on diamond networks [64]. It was pointed out that the faradaic current of $\mathrm{Fe}(\mathrm{CN}) 6^{3-/ 4-}$ is dominated by its diffusion length, which is typically in the range of tens of micrometers. Since the distance in between nanowires or diamond pores is much smaller than the diffusion length of $\mathrm{Fe}(\mathrm{CN})_{6}{ }^{3-/ 4-}$, diamond nanowires or diamond network based electrodes actually behaved as a planar macroscopic electrode [30].

The length and the surface termination of diamond nanowires influenced electrochemical response of redox probes [30,35]. For example, Szunerits and co-workers [35] have shown that the shorter and oxidized diamond nanowires give smaller redox currents and thus slower electron transfer processes (Figure 3). They employed boron-doped diamond nanowires with lengths of $1.0 \pm 0.3 \mu \mathrm{m}$, tip radia of $50 \pm 10 \mathrm{~nm}$, base radia of $200 \pm 50 \mathrm{~nm}$, average spacings of 8-100 nm, and the density of $(5 \pm 3) \times 10^{8} \mathrm{~cm}^{-2}$ as short nanowires, and those needle-like nanowires with lengths of $3 \pm 0.2 \mu \mathrm{m}$, diameters of $10-50 \mathrm{~nm}$, and the density of $(15 \pm 3) \times 10^{8}$ $\mathrm{cm}^{-2}$ as long nanowires. Hydrogen termination of these nanowires was done in an ultra high vacuum CVD chamber using a hot-filament CVD mode. On hydrogen terminated diamond nanowires, reversible redox behavior of $\mathrm{Fe}(\mathrm{CN})_{6}{ }^{4-}$ was seen. For short and long nanowires, these redox peak currents were about 2.4 and 3.5 times higher than those obtained on the flat diamond electrode, respectively. The peak currents were proportional to the square root of the 
scan rates, as expected for a diffusion-limited process. While on oxidized nanowires, quasireversible electrochemical behaviour of $\mathrm{Fe}(\mathrm{CN})_{6}{ }^{4-}$ was noticed.
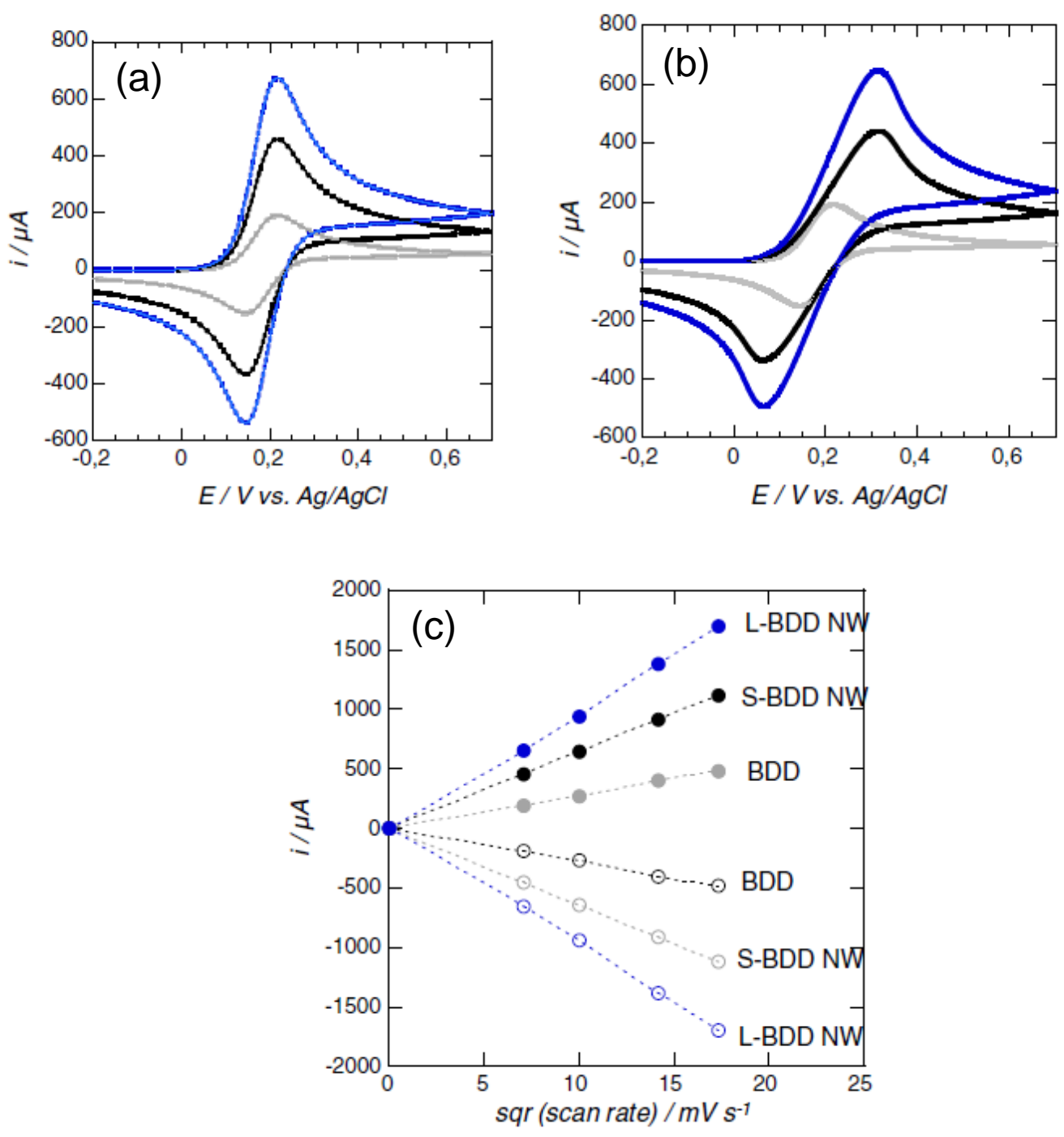

Figure 3. Length and termination effect on electrochemistry of nanowires. Cyclic voltammograms of initial boron-doped diamond film (grey), short diamond nanowires (black) and long diamond nanowires (blue): (a) H-terminated electrodes; experimental data (dotted lines), Digi Sim fitted data (full lines); (b) oxidized electrodes: solution: $10 \mathrm{mM} \mathrm{Fe}(\mathrm{CN})_{6}{ }^{4-}+$ $0.1 \mathrm{M} \mathrm{KCl}$, scan rate: $0.05 \mathrm{~V} \mathrm{~s}^{-1}$; geometric area $=0.1 \mathrm{~cm}^{2}$, (c) Variation of anodic $(\bullet)$ and cathodic (०) peak current with the square root of scan rate for boron-doped diamond film (grey), short diamond nanowires (black) and long diamond nanowires (blue). (Reproduced with permission from Ref. [35] Copyright 2014, Elsevier).

\subsection{Voltammetry on diamond nanoelectrodes}

Small-dimensional electrodes (e.g., ultramicroelectrode, nanoelectrodes, etc.) offer various benefits over planar macroscopic electrodes, such as reduced Ohmic resistance, enhanced 
mass transport, decreased charging currents and deleterious effects of solution resistance, as well as high possibility for fast voltammetric measurements [156-160]. However, single small-dimensional electrode only generates small current that is relatively difficult to detect with conventional electrochemical setups. This has been circumvented by fabricating its arrays or ensembles that operate in parallel. These arrays and ensembles amplify the signal of individual small-dimensional electrodes but do not lose the beneficial characteristics of individual electrodes. If they are applied for sensor applications, their performances with respect to the sensitivity, detection limit, and reproducibility will be highly improved [156162]. Since a macroscopic diamond electrode shows a higher degree of inhomogeneity with respect to boron-doping level and termination effects due to its macroscopic dimensions, one would expect a homogenized behavior on a diamond NEA or NEE $[154,155]$, due to small grains of diamond films and a more effective termination on small electrochemical active areas.

Diamond NEAs were characterized for the first time with Scanning Electrochemical Microscopy (SECM) [166]. Using the phase-operated shear force technique and feedback mode, scanning a platinum nanoelectrode with an active radius of $167 \mathrm{~nm}$ over a diamond NEA was realized at a constant distance of $45 \mathrm{~nm}$. With a lateral resolution within a $100 \mathrm{~nm}$ range, the electrochemical activity of single diamond nanoelectrodes (320 nm in diameter) and the arrangement of these diamond nanoelectrodes were detected [166]. Diamond NEEs were characterized with conductive atomic force microscope (C-AFM) [154]. The density determined by C-AFM was $8.5 \times 10^{5} \mathrm{~cm}^{-2}$, which was in good agreement with the expected values from $\mathrm{SiO}_{2}$ sphere concentration in the solution. The size of electrodes was $175 \mathrm{~nm}$ in radius. The cross sections of the topography for two neighboring electrodes clarified that these conductive nanoelectrodes were surrounded by insulating diamond with a thickness of $140 \mathrm{~nm}$.

The voltammograms of $\mathrm{Fe}(\mathrm{CN}) 6^{3-/ 4-}$ on diamond NEA and NEE at small scan rates (e.g., 20 $\mathrm{mV} \mathrm{s}^{-1}$ for the NEA and $1 \mathrm{mV} \mathrm{s}^{-1}$ for the NEE) showed mixed shapes, namely between peakshaped voltammogram and sigmoidal voltammogram [154]. Increasing scan rates led to typical steady-state sigmoidal voltammograms on both electrodes. It was suggested that partially overlapped diffusion hemispheres occured on both NEA and NEE at slow scan rates, while sphere-diffusion did at high scan rates because the variation of scan rates determined the diffusion layer thicknesses of analytes. The recorded electrochemical impedance spectra 
on both NEA and NEE displayed a large semicircle in the high-frequency regime, suggesting a three-dimensional hemispherical diffusion [163-165]. At low frequencies, a transition to linear diffusion with unity slope appeared, particularly observable for the NEA. This transition represented the regime of overlapping diffusion hemispheres. The change from typical three-dimensional diffusion to overlapping diffusion hemispheres was very distinct on NEA.

The voltammetric response of $\mathrm{Ru}\left(\mathrm{NH}_{3}\right)_{6}{ }^{2+/ 3+}$ and $\mathrm{IrCl}_{6}{ }^{2-/ 3-}$ on a diamond NEA [154] showed the dependence of surface termination on the charge of the analytes (Figure 4). Notably on planar macroscopic diamond electrodes both analytes showed no dependence of electron transfer rate constant on the surface termination of diamond electrode. On the hydrogen terminated diamond NEA, the voltammogram of the anion $\mathrm{IrCl}_{6}{ }^{2-13-}$ showed a fast electron transfer while at the oxygen terminated surface, the steady-state current as well as the slope of the transition from reduction to oxidation decreased, indicative of a slower electron transfer. This tendency was similar for another negatively charged redox couple of $\mathrm{Fe}(\mathrm{CN}) 6^{3-/ 4-}$. However, the opposite effect was observed for the positively charged redox molecules $\mathrm{Ru}\left(\mathrm{NH}_{3}\right)_{6}{ }^{2+/ 3+}$. It was explained that that hydrogen terminated surface had positive surface dipole layer ("positive" referred to the interface of diamond to the liquid) and the oxygen terminated surface resulted in negative surface dipole layer. Such behaviors were therefore attributed to either an electrostatic or a site blocking effect [163-165].

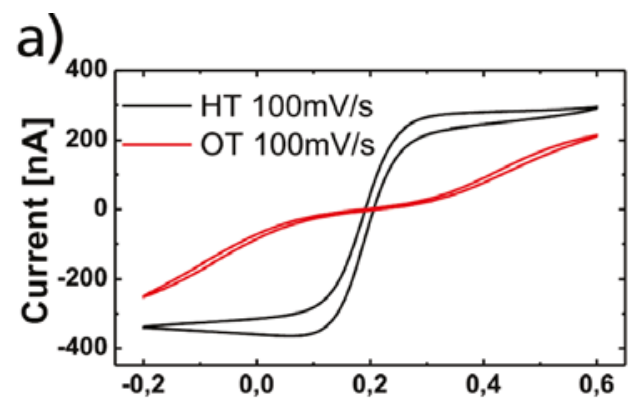

C)

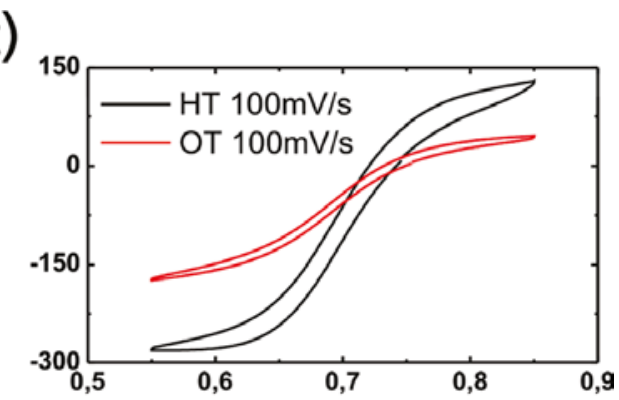

Ewe (V) vs. $\mathrm{Ag} / \mathrm{AgCl} / \mathrm{KCl}(1 \mathrm{M})$

b)

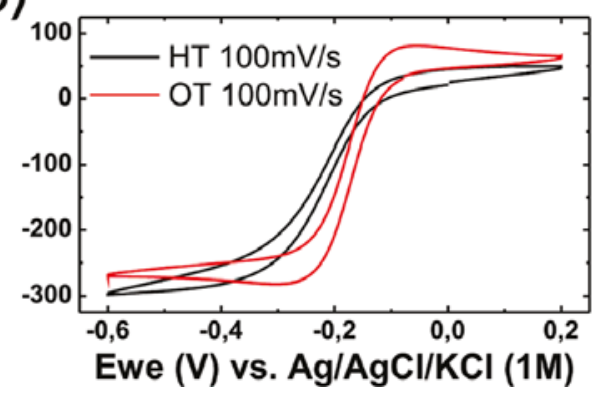

d)
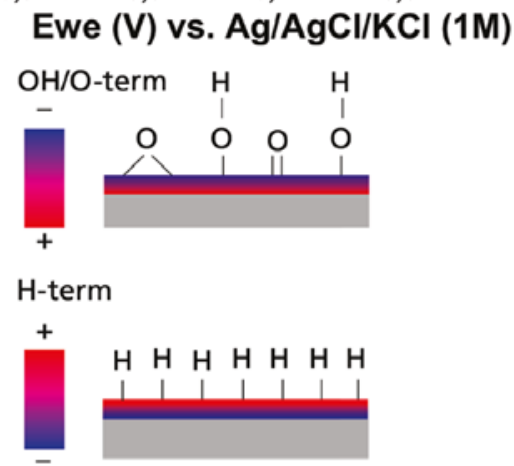

Figure 4. Termination and charge effect on voltammetry of diamond NEA. Comparison of voltammograms of (a) $\mathrm{Fe}(\mathrm{CN})_{6}^{3-/ 4-}$, (b) $\mathrm{Ru}\left(\mathrm{NH}_{3}\right)_{6}{ }^{2+/ 3+}$, and (c) $\mathrm{IrCl}_{6}{ }^{2-/ 3-}$ on hydrogen- $(\mathrm{HT})$ 
and oxygen (OT)- terminated diamond NEAs. (d) Schematic plots of the charge distribution on a HT- and OT- diamond surface. (Reproduced with permission from Ref. [154] Copyright 2011, ACS Publisher)

\subsection{Electrochemical activity of diamond particles}

To investigate electrochemical activity of diamond nanoparticles, diamond nanoparticles were always treated and/or cleaned. The applied processes include acid boiling, oxidation by Oswald method, plasma treatment, thermal annealing, etc. For example, acid boiling removed effectively the responses associated with $\mathrm{sp}^{2}$ carbon impurities. Surface treatment of diamond nanoparticles by heating in air or in hydrogen flow resulted in oxygen and hydrogen terminated nanoparticles, respectively.

On these diamond nanoparticles based film electrode, a potential independent capacitive signal has been obtained via recording their cyclic voltammograms in solutions without any redox species. Diamond nanoparticle based film electrodes have been fabricated with various techniques, such as drop coating from ethanol suspensions, smearing a mineral oil paste of diamond nanoparticles, grinding diamond powders into the tip of a Pt wire sealed in a small pipette, electrophoretically deposition, co-deposition, non-contact microprinting, and layerby-layer self-assembly by a high pressure/high-temperature methodology.

\subsubsection{Un-doped diamond nanoparticles}

Un-doped diamond nanoparticles showed different electrochemical properties from their bulk diamond. They were surprisingly electrochemically active, depending on the nature/type (e.g., denotation, HPHT particles, etc.), surface terminations, and the $\mathrm{pH}$ value of the solutions.

\subsubsection{Detonation diamond nanoparticles}

Novoselova et al. [79] studied for the first time electrochemical activity of diamond powders in aqueous electrolytes. Redox couples of $\left[\mathrm{Fe}(\mathrm{CN})_{6}\right]^{3-/ 4-}$ and $\mathrm{Ce}^{3+/ 4+}$ were applied as probes. The voltammetric response of $\mathrm{Fe}(\mathrm{CN})_{6}{ }^{3-/ 4-}$ was superimposed on a linearly sloping background and with small peak currents. The reduction currents were two times larger than the oxidation currents. In the case of the $\mathrm{Ce}^{3+/ 4+}$ redox couple, additional current responses were noted, besides the expected current peaks. 
Zang et al. [80] used cavity electrodes to investigate electrochemical activity of diamond nanoparticles. Stable background currents over a wide potential range (-1.2-2.0 V) in $\mathrm{KCl}$ solution was obtained coupled with a quasi-reversible reversible electrode reaction for the $\mathrm{Fe}(\mathrm{CN}) 6^{3-/ 4-}$, of which electrode reaction rate constant was $2.87 \times 10^{-3} \mathrm{~cm} \mathrm{~s}^{-1}$. The recorded AC impedance spectra were consistent with those obtained on a porous electrode.

Various techniques have been then applied to investigate electrochemical activity of diamond nanoparticles. For example, attenuated total reflectance infrared spectroscopy was used to monitor spectral features of the surface of diamond nanoparticles [82]. Aqueous $\mathrm{IrCl}_{6}{ }^{2-}$ was added in these studies. Electron transfer between the surface of diamond nanoparticle and the solution redox species resulted in the oxidation of $8.5 \%$ of surface alcohol groups, with concomitant formation of unsaturated ketone or quinone-like moieties [82]. SECM was applied [83] to investigate the redox behaviour of detonation diamond nanoparticles based film electrode. Different collection modes and various redox mediators were employed to estimate quantitatively heterogeneous rate constants and overpotentials of redox probes (Figure 5). Approach curves were recorded at diamond nanoparticles based film electrode at a range of substrate overpotentials, $\eta$, with $|\eta|=0.2$ to 0.6 V. For experimental approach curves obtained using $1 \mathrm{mM} \mathrm{Fe}(\mathrm{CN})_{6}{ }^{3-}$ and $1 \mathrm{mM} \mathrm{Fe}(\mathrm{CN})_{6}{ }^{4-}$, the current decreased as the tip approached the surface of diamond nanoparticles, as expected for pure negative feedback to an insulator. This was explaned by that the experimental current was a combination of negative feedback due to blocking of fresh reactant diffusion to the tip and the positive feedback obtained from regeneration of reactant at diamond nanoparticles. However the rate of regeneration (positive feedback) was quite small in all cases, so the tip current experienced an overall drop as the tip was approaching to the surface of diamond nanoparticles. Note that for the redox mediator $\mathrm{Fe}(\mathrm{CN})_{6}{ }^{3-}$ the process of interest was actually the oxidation of the tipgenerated $\mathrm{Fe}(\mathrm{CN})_{6}{ }^{4-}$ at the surface of diamond nanoparticles; likewise for the $\mathrm{Fe}(\mathrm{CN}) 6^{4-}$ mediator monitoring the reduction of the tip-generated $\mathrm{Fe}(\mathrm{CN}) 6^{3-}$ at the surface of diamond nanoparticles. It was found that extremely sluggish kinetics were found on the surface of diamond nanoparticels for all redox couples, but the reduction of $\mathrm{Fe}(\mathrm{CN})_{6}{ }^{3-}$ was especially slow when compared to the oxidation of $\mathrm{Fe}(\mathrm{CN})_{6}{ }^{4-}$. Overall, the rate constants were about 10 times faster at the diamond nanoparticles based film electrode than that on the boron-doped diamond film [83]. Supported with in-situ ATR (attenuated total reflectance)FTIR (Fourier transform infrared) experimental results, electron transfer at the diamond nanoparticle surface has been suggested to take place at similar sites as on the boron-doped 
diamond film. But the reaction sites were presented at higher relative concentrations due to the higher surface to bulk atom ratio of the nanoparticles [86].
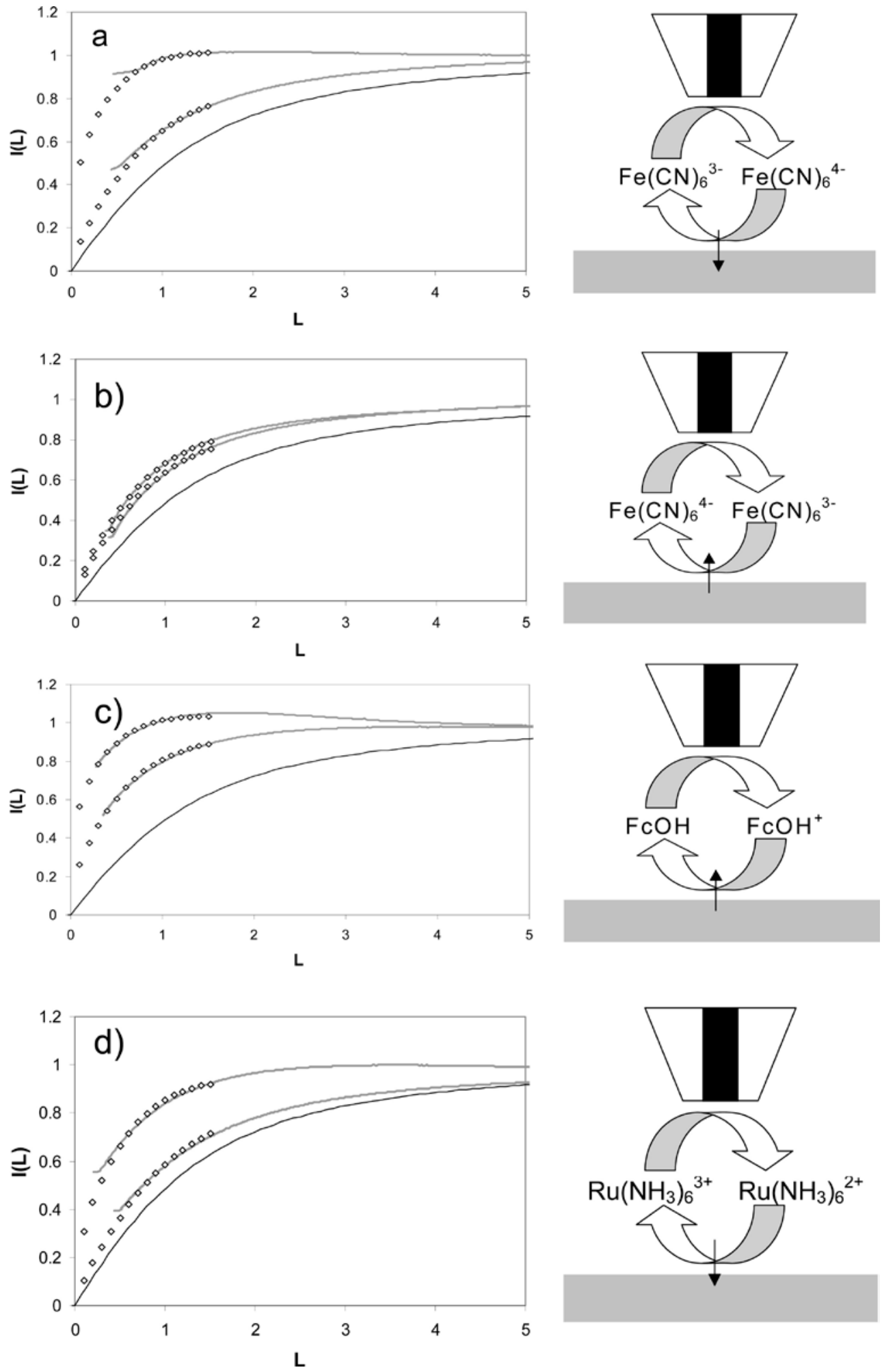

Figure 5. SECM on diamond nanoparticles. Left: Experimental approach curves (gray) to ND film at $|\eta| 0.2 \mathrm{~V}$ (lower) and $0.6 \mathrm{~V}$ (upper) with $10 \mu \mathrm{m}$ Pt tip, RG $=3$ at approach rate of 5 $\mu \mathrm{m} \mathrm{s}^{-1}$. Black curve, theoretical approach curve to an insulating surface for tip with RG = 3; open diamonds, fit to theory for different $k_{\text {expt }}$ (a) Mediator $1 \mathrm{mM} \mathrm{Fe}(\mathrm{CN})_{6}{ }^{3-}: E_{\text {tip }}=0.0 \mathrm{~V}$; $|\eta|$ 


$$
=0.2 \mathrm{~V}\left(E_{\mathrm{S}}=0.4 \mathrm{~V}\right), k_{\text {expt }}=0.0008 \mathrm{~cm} \mathrm{~s}^{-1} ;|\eta|=0.6 \mathrm{~V}\left(E_{\mathrm{S}}=0.8 \mathrm{~V}\right), k_{\text {expt }}=0.005 \mathrm{~cm} \mathrm{~s}^{-1} \text {. }
$$

Mediator $1 \mathrm{mM} \mathrm{Fe}(\mathrm{CN})_{6}{ }^{4-}: E_{\text {tip }}=0.5 \mathrm{~V} ;|\eta|=0.2 \mathrm{~V}\left(E_{\mathrm{S}}=0.0 \mathrm{~V}\right), k_{\text {expt }}=0.0007 \mathrm{~cm} \mathrm{~s}^{-1} ;|\eta|=$ $0.6 \mathrm{~V}\left(E_{\mathrm{S}}=-0.4 \mathrm{~V}\right), k_{\text {expt }}=0.001 \mathrm{~cm} \mathrm{~s}^{-1}$. (c) Mediator $1 \mathrm{mM} \mathrm{FcOH:} E_{\text {tip }}=0.5 \mathrm{~V} ;|\eta|=0.2 \mathrm{~V}$ $\left(E_{\mathrm{S}}=0.0 \mathrm{~V}\right), k_{\text {expt }}=0.002 \mathrm{~cm} \mathrm{~s}^{-1} ;|\eta|=0.6 \mathrm{~V}\left(E_{\mathrm{S}}=-0.4 \mathrm{~V}\right), k_{\text {expt }}=0.006 \mathrm{~cm} \mathrm{~s}^{-1}$. (d) Mediator $1 \mathrm{mM} \mathrm{Ru}\left(\mathrm{NH}_{3}\right)_{6}{ }^{3+}: E_{\text {tip }}=-0.3 \mathrm{~V} ;|\eta|=0.2 \mathrm{~V}\left(\mathrm{Es}_{\mathrm{S}}=0.1 \mathrm{~V}\right), k_{\text {expt }}=0.0004 \mathrm{~cm} \mathrm{~s}^{-1} ;|\eta|=0.6 \mathrm{~V}$ $\left(E_{\mathrm{S}}=0.5 \mathrm{~V}\right), k_{\text {expt }}=0.003 \mathrm{~cm} \mathrm{~s}^{-1}$. Right: Schematics of redox processes taking place at the tip and at the diamond nanoparticle based film surface. Black arrows indicate direction of electron transfer at the film interface. (Reproduced with permission from Ref. [83] Copyright 2009, ACS Publisher)

Holt and her colleague [81-86] made extensive investigation on electrochemical activity of detonation diamond nanoparticles. Differential pulse voltammetry of electrode-immobilised layers of diamond nanoparticles in the absence of redox species revealed oxidation and reduction peaks, resulting from direct electron transfer reactions of diamond nanoparticles themselves [81]. The presence of detonation diamond nanoparticles on the (diamond) electrode modified the cyclic voltammetric response of $\mathrm{Fe}(\mathrm{CN})_{6}{ }^{3-/ 4-}$ and $\mathrm{IrCl}_{6}{ }^{3-/ 2-}$ when the scan rate was slow and the concentration of redox couples was low. For example, enhancements of oxidation currents were noted at potentials where the oxidation of the surface of diamond nanoparticles started. The enhancements of reduction currents were likewise observed where diamond nanoparticle was reducible [81]. Moreover, redox activity of detonation diamond nanoparticles was found to be affected by $\mathrm{pH}$ values of the solution, namely by the proton concentration. In the solutions with $\mathrm{pH}$ value of 4 and 5 , well-defined peaks in the potential range of -0.1 to $0.5 \mathrm{~V}$ (vs. $\mathrm{Ag} / \mathrm{AgCl}$ ) were seen from differential pulse voltammograms. As the solution $\mathrm{pH}$ increased, they became much smaller in magnitude and far less resolved. This was explained by that electrochemical response of diamond nanoparticles resulted from the oxidation and reduction of surface states of diamond nanoparticles. The potentials of these surface states were $\mathrm{pH}$-dependent and able to interact with solution redox species as well [81,83].

To explain such 'molecule-like' electrochemical activity of diamond nanoparticles, Holt et al. proposed a feedback mechanism. It was proposed that surface functionalities, defect sites and unsaturated bonding gave rise to surface electronic states with energies within the band gap of undoped diamond nanoparticles. These surface states acted as a source and sink of as both electron donors and acceptors for the promotion of solution redox reactions. When specific 
redox-active molecules were present, catalytic redox processes occured. In other words, a self-conducted oxidation and reduction process via surface states at specific potentials triggered the redox activities of diamond nanoparticles. The magnitude of current enhancement was dependent on the standard potential of the redox couple relative to surface states of diamond nanoparticles. Provided that at the nanoscale surface properties of diamond nanoparticles dominated over those of the bulk, electron transfer occured between electroactive species generated at the underlying electrode during voltammetry and the immobilized diamond nanoparticles in the interfacial region, leading to regeneration of the starting species and hence enhancement in currents. For example, a species such as FcMeOH undergoes oxidation at an electrode to produce $\mathrm{FcMeOH}^{+}$. In the presence of diamond nanoparticles, the $\mathrm{FcMeOH}^{+}$is then reduced by redox active functionalities on the surface of diamond nanoparticles, resulting in regeneration of FcMeOH. This continual regeneration of FcMeOH in the electrode diffusion layer results in an enhanced catalytic current, so-called a feedback mode. This catalytic current was found later to be affected by the size of diamond nanoparticles, the $\mathrm{pH}$ and ionic strength of the solutions, scan rate, and the amount of adsorbed redox species (e.g., FcMeOH) [86]. For example, the enhancement of redox currents for reversible oxidation of ferrocene methanol was dependence of the diameter of diamond nanoparticles in the order $1000 \mathrm{~nm}<250 \mathrm{~nm}<100 \mathrm{~nm}<10 \mathrm{~nm}<5 \mathrm{~nm}$ [64]. These experimental facts were then explained with a catalytic feedback mechanism (Figure 6). Briefly, solution FcMeOH undergoes electron exchange with adsorbed $\mathrm{FcMeOH}^{+}$to generate solution $\mathrm{FcMeOH}^{+}$and adsorbed FcMeOH. The adsorbed FcMeOH is re-oxidised to adsorbed $\mathrm{FcMeOH}^{+}$by the underlying diamond electrode, or by a redox process with surface groups of diamond nanoparticles. Thus, in addition to the catalytic currents generated by the feedback mechanism, the adsorbed species mediate a catalytic process. The accumulative influence of both processes leads to significantly enhanced redox currents.

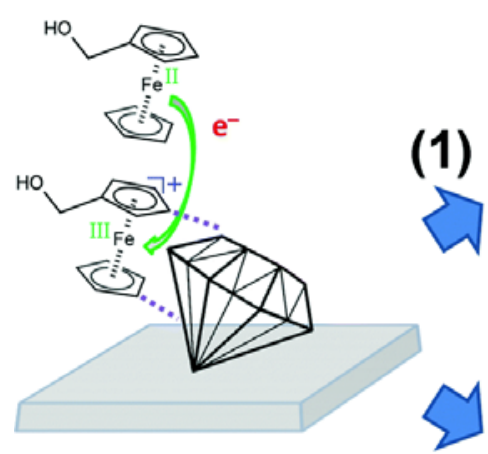

(2)
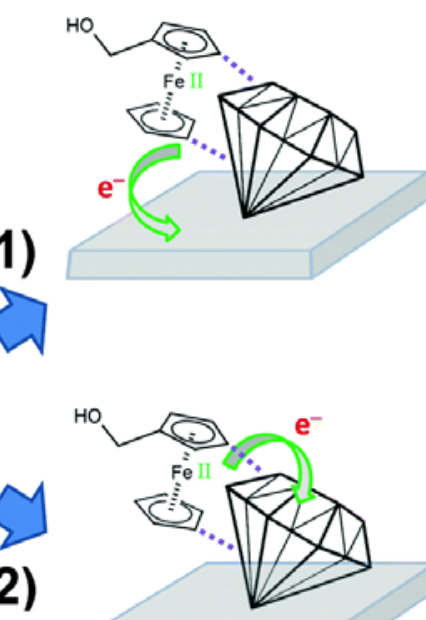

19
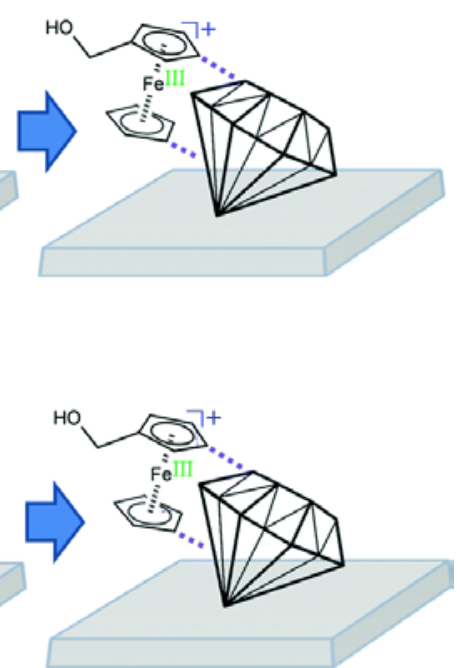
Figure 6. Catalytic feedback mechanism on diamond nanoparticles. Illustration of nanodiamond surface adsorbed $\mathrm{FcMeOH}^{+}$and its associated redox reaction. Re-oxidation of the FcMeOH product can then occur by either (1) the underlying electrode (when at sufficient potential) or (2) reaction with nanodiamond surface functionalities. The green arrows depict the direction of electron transfer. (Reproduced with permission from Ref. [86], Published by The Royal Society of Chemistry)

Electrochemical activity of redox probes on detonation diamond nanoparticles (5 $\mathrm{nm}$ in diameter) was found to be tuneable via surface terminations/functionalization and graphitization of diamond nanoparticles [87,88]. For example, both redox reactions of $\mathrm{Fe}(\mathrm{CN})_{6}{ }^{3-/ 4-}$ and $\mathrm{Fe}^{2+/ 3+}$ were quasi-reversible on the pristine diamond nanoparticles based film electrodes. Oxygen terminated diamond nanoparticles were found to exhibit the greatest electrochemical activity for the redox couples $\mathrm{Ru}\left(\mathrm{NH}_{3}\right)_{6}{ }^{2+/ 3+}$ and $\mathrm{Fe}(\mathrm{CN}) 6^{3-/ 4-}$, hydrogen terminated diamond nanoparticles the least. After fluorination of diamond nanoparticles, the electrode reactions of $\mathrm{Fe}(\mathrm{CN})_{6}{ }^{3-/ 4-}$ became slower. The amino modification accelerated the electron transfer process of $\mathrm{Fe}(\mathrm{CN})_{6}{ }^{3-/ 4-}$ anions but slowed the redox reaction of $\mathrm{Fe}^{2+/ 3+}$ cations [88]. Annealing of diamond nanoparticles in vacuum led to the variation of electrochemical activities of diamond nanoparticles. The charge transfer rate of the $\mathrm{Fe}(\mathrm{CN})_{6}{ }^{3-/ 4-}$ redox couple in aqueous solutions decreased with an increase of the annealing temperature. Re-annealing in air restored the original redox activity. This was because vacuum annealing below $850{ }^{\circ} \mathrm{C}$ removed parts of the oxygen-containing surface functionalities from the surface of diamond nanoparticles and produced more $\mathrm{sp}^{2}$ carbon atoms in the shell. When the annealing temperature was at $900-1100{ }^{\circ} \mathrm{C}$, more serious graphitization produced a continuous fullerenic shell wrapped around a diamond core, which had a high conductivity and electrochemical activity [87].

\subsubsection{HPHT diamond nanoparticles}

Fermin et al. [89-92] combined zeta potential measurements in solutions and electrochemical studies in thin layer assemblies of diamond nanoparticles to investigate electrochemical properties of undoped HPHT diamond particles. The estimated point-of-zero zeta potential was 6.6. The zeta potentials of these nanoparticles depended on $\mathrm{pH}$. In a single electron transfer process, 10000 redox centres per particle were involved. Electrochemical signals were rather sensitive to the extent of $\mathrm{sp}^{2}$ hybridisation at the surface of diamond powders [89]. Electrochemical field-effect transistors were employed to investigate the charge transport 
properties of oxygen and hydrogen terminated diamond particles in the presence and absence of metal nanostructures [90]. The assembly of hydrogen terminated diamond particle was characterized by a charging process at a potential above $0.1 \mathrm{~V}$ (vs. $\mathrm{Ag} / \mathrm{AgCl}$ ). The responses were found to be associated with hole-injection into the valence band edge, which shifted to approximately $-4.75 \mathrm{eV}$ (vs. vacuum) upon hydrogenation. The position of the valence band edge and hole number density at the surface of hydrogen terminated diamond particles varied as a function of the applied potential [91]. Through the discussion in terms of the electrochemical formation of charge carriers in the diamond particles, percolation theory, and charge screening at the double layer [92], charge transport on un-doped diamond particles was suggested to be determined not only by the intrinsic surface conductivity of individual diamond particles but also particle-to-particle charge transfer. The latter contribution effectively controlled the assembly conductivity in the presence of an electrolyte as the difference between hydrogen and oxygen terminated particles vanished. The conductivity in the presence of metal nanoparticles was mainly determined by the metal volume fraction, while diamond surface termination and the presence of electrolyte solutions exerted only minor effects.

\subsubsection{Doped diamond particles}

To check electrochemical activities of boron-doped diamond particles, redox probes of $\mathrm{Fe}(\mathrm{CN}) 6^{3-4-}$ and $\mathrm{Ru}\left(\mathrm{NH}_{3}\right)_{6}{ }^{3+/ 2+}$ and a polytetrafluoroethylene binder were used. These particles were produced via MPCVD growth of a thin boron-doped layer on insulating diamond powders (8-12 $\mu \mathrm{m}$ in diameter). At scan rates between 10 and $500 \mathrm{mV} \mathrm{s}^{-1}$, the peak difference of the anodic wave from the cathodic wave was high (in the range 0.14 to $0.35 \mathrm{~V}$ ) for both redox probes, suggesting significant ohmic resistance within the powder/binder electrode [143]. The same technique was applied then to overgrow small-sized diamond powders (100 and $500 \mathrm{~nm}$ in diameter). Both powders had increased conductivities. Welldefined electrochemical responses for the redox reactions of $\mathrm{Fe}(\mathrm{CN}) 6^{3-4-}, \operatorname{Ir}(\mathrm{Cl}) 6^{2-\beta^{-}}$, and $\mathrm{Fe}^{2+\beta+}$ were obtained on these powders based film electrode, in comparable to typical responses shown on the high-quality, boron-doped nanocrystalline diamond thin-film [144]. Later electrochemical characteristics of boron-doped diamond powders based film electrodes were investigated by measuring the cyclic voltammetric curves and AC impedance spectra [145]. The powders were synthesized under HPHT using B-doped graphite intercalation compositions as carbon sources. For the $\left[\mathrm{Fe}(\mathrm{CN})_{6}\right]^{3-/ 4-}$ redox couple, the electrode reaction process was reversible or quasi-reversible at the scan rates of $0.01-1.0 \mathrm{~V} \mathrm{~s}^{-1}$. At the low scan 
rate the linear relation was found between peak current and square root of scan rate, similar to that obtained a planar electrode. These indicated that the electrode process on these powders was a diffusion-controlled mass transport process. With the increasing of the scan rate the electrode process was varied and controlled by the mass transport plus kinetic process. AC impedance spectra exhibited the porous structure characteristic of boron-doped diamond powders based film electrode [145]. The boron-doped diamond nanoparticles made by solidstate diffusion method showed a lower capacitance and higher conductivity than undoped diamond nanoparticles [146]. In the potential range of -0.3 to $1.8 \mathrm{~V}$ (vs. SCE), a featureless voltammetric response was obtained. Recently high quality boron-doped diamond nanoparticles with a size of 10-60 $\mathrm{nm}$ and a boron concentration of approximately $2.3 \times 10^{21} \mathrm{~cm}^{-3}$ have been produced [147]. However, electrochemistry of those nanoparticles has not been reported.

\section{Electrochemical applications of diamond nanostructures and particles}

\subsection{Electroanalysis}

Diamond nanostructures and particles have improved reactive site, promoted electrocatalytic activity, accelerated electron transfer rates, and are therefore promising electrodes for electroanalysis to improve the selectivity, sensitivity and reproducibility of electrochemical and bioelectrochemical sensors.

\subsubsection{Diamond nanostructures}

Diamond nanostructures have been widely applied for the development of electrochemical and bioelectrochemical sensors, such as for determination of dopamine in the presence of ascorbic acid and uric acid [32,33], non-enzymatic monitoring of glucose [34-36], the detection and immobilization of biomolecules (e.g., tryptophan [37,38], tyrosine [38], catechol [39], cytochrome c (cyt. c) [40-42], and shewanella loihica PV-4 [43], etc.), as well as for the construction of toxicity sensor [44]. The performance of some reported sensors is summarized in Table 1. For example, diamond nanowires allowed non-enzymatic oxidation of glucose [34]. This process is fast (less than 20 s) and stable (only 8\% reduction after 150 repetitive cycles). At $0.7 \mathrm{~V}$ (vs. SCE), the steady-state oxidation current was linearly enhanced with the concentration of glucose from 0 to $7 \mathrm{mM}$ with a sensitivity of $8.1 \mu \mathrm{AmM}^{-1}$ $\mathrm{cm}^{-2}$. The detection limit was $0.2 \pm 0.01 \mu \mathrm{M}$ [34]. Such kind of non-enzymatic glucose detection was found further to be affected remarkably with the length and the surface terminations of diamond nanowires as well as the $\mathrm{pH}$ values of the buffer solutions [35]. Thus 
for non-enzymatic glucose detection different detection limits have been reported ranging from $5.0 \mathrm{mM}$ to $60 \mu \mathrm{M}$ [35]. Simultaneous detection of tryptophan and tyrosine was conducted successfully as well by differential pulse voltammetry on diamond nanowires when the amount ratio of tryptophan to tyrosine was less than 0.5 [38].

Table 1. Electrochemical sensing performance on diamond nanostructures and particles

\begin{tabular}{|c|c|c|c|c|}
\hline Electrode $^{*}$ & Analyte & $\begin{array}{l}\text { Linear range } \\
(\mu \mathrm{M})\end{array}$ & $\begin{array}{l}\text { Detection limit } \\
(\mathrm{nM})\end{array}$ & Ref \\
\hline \multirow{6}{*}{ Dia NWs } & dopamine & $5-120$ & 800 & [32] \\
\hline & \multirow{2}{*}{ glucose } & $0-7000$ & $200 \pm 10$ & [34] \\
\hline & & $10000-50000$ & 60000 & [35] \\
\hline & catechol & $5-100$ & 1300 & [39] \\
\hline & tryptophan & & & [38] \\
\hline & tyrosine & & & [38] \\
\hline N-doped Dia NWs & dopamine & $0.5-10$ & 360 & [33] \\
\hline \multirow{3}{*}{ Ni NPs/Dia NWs } & olusoco & & 10 & [35] \\
\hline & grucose & $10-1000$ & & {$[36]$} \\
\hline & IgG & $0.3-400^{* *}$ & $0.3^{* *}$ & [49] \\
\hline Chitosan/nanographite & azathioprine & $0.2-100$ & 65 & \multirow{2}{*}{ [93] } \\
\hline /Dia NPs & epinephrine & $0.01-10$ & 3 & \\
\hline Dia NPs & uric acid & $0.01-60$ & 3 & [94] \\
\hline \multirow{2}{*}{ Nanographite/Dia NPs } & tryptophan & & 30 & \multirow{2}{*}[96]{} \\
\hline & 5-hydroxytryptophan & & 6 & \\
\hline \multirow{2}{*}{ Ag NPs/Dia NPs } & thioridazine & $0.08-100$ & 10 & [97] \\
\hline & hydrogen peroxide & $0.1-34.0$ & 10 & [98] \\
\hline $\mathrm{TiO}_{2}$ NPs/Dia NPs & nitrite & $50-1000$ & 550 & [99] \\
\hline Cyt c/Dia NPs & nitrite & $500-3000$ & 160 & {$[102]$} \\
\hline HRP/Dia sponges & hydrogen peroxide & $1000-45000$ & 59000 & [104] \\
\hline LOx/Dia NPs & lactate & $50-700$ & 15000 & [106] \\
\hline
\end{tabular}

* Dia: diamond; NW: nanowire; NP: nanoparticle; Cyt c: cytochrome c; HRP: horseradish peroxidase; sponges: porous poly(aniline)-poly(2-acrylamido 2-methyl propane sulfonic acid) network; LOx: lactate oxidase

*** unit: ng $\mathrm{mL}^{-1}$ 
Diamond nanograss has been employed as the working electrodes in an electrochemical cell inoculated with S. loihica PV-4. The role of diamond nanograss array in promoting electron transfer from the intracellular environment to the electrode surface has been demonstrated [43]. By use of such a shewanella loihica (S. loihica ) PV-4 planktonic cell as recognition element in bioelectrochemical systems (BES), a toxicity sensor based on the electrochemical and impedance detection of tobramycin was proposed [44]. An oxidative current density of $3.3 \mathrm{~A} \mathrm{~cm}^{-2}$ was generated on diamond nanograss based electrode poised at $0.2 \mathrm{~V}$ in the BES, in the presence of $S$. loihica PV-4 cells. After addition of tobramycin in the range of $1.0-20.0$ $\mathrm{g} \mathrm{mL}^{-1}$, the current density decreased from $3.0 \mathrm{~A} \mathrm{~cm}^{-2}$ to $1.3 \mathrm{~A} \mathrm{~cm}^{-2}$, with current inhibition ratio exponentially increased from $7.6 \%$ to $59.6 \%$. The redox peak currents obtained from cyclic voltammograms reduced exponentially with tobramycin concentrations. The semicircle diameter of impedance spectra increased with the increase of tobramycin concentration.

The composition (e.g., ratio of graphite to diamond, etc.), surface termination, and morphology (e.g., length, size, density, etc.) of diamond nanowires affected greatly their electrochemical and electrocatalytic activities, and eventually their sensing performance. Figure 7 shows an example of electrocatalytic activity of N-doped diamond nanowires towards the oxidation of ascorbic acid, dopamine, and uric acid. The diamond nanowires grown at different temperatures showed varied catalytic activities, resulting from the increased $\mathrm{sp}^{2}$ graphitic phase and nanowire-like structure [33]. A more efficient and faster electron transfer process of cyt c was realized on $\mathrm{OH}$-terminated (or partially oxidized) diamond nanotextures [40-42]. Such an electrode system was named as an artificial molecular trap [42]. The enhancement of electron transfer rate resulted from the electrostatic and hydrophobic interaction of cyt c with OH-terminated diamond, confirmed by electrocatalytic oxygen reduction reaction as well as AFM scratching experiments in liquid [45-47]. The electrostatic interaction controlled coarse orientation of cyt c while hydrophobic interaction assisted in the formation of the electron transfer complex. 

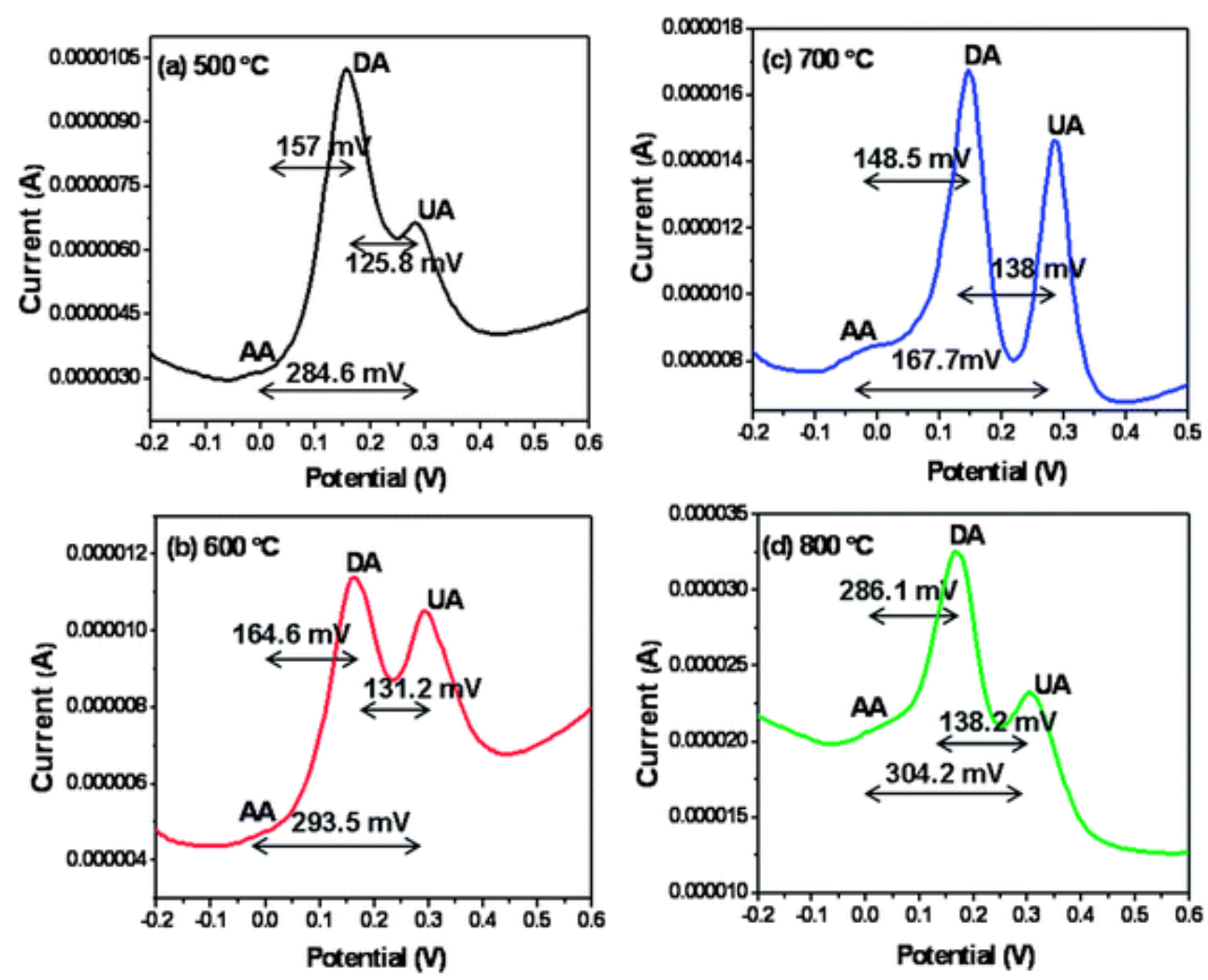

Figure 7. Morphology effect on electrochemical sensing. Differential pulse voltammetry curves for diamond nanowires based film electrodes in a solution containing $0.33 \mathrm{mM}$ ascorbic acid (AA) $+0.033 \mathrm{mM}$ dopamine (DA) $+0.033 \mathrm{mM}$ uric acid (UA). The diamond nanowires were grown at the temperature of 500 (a), 600 (b), 700 (c), and 800 (d) ${ }^{\circ}$ C. (Reproduced with permission from Ref. [33], Published by The Royal Society of Chemistry)

Decorated diamond nanostructures with metal nanoparticles [36,48-50] and with nitrophenyl linker [51,52,54] were applied to construct electrochemical non-enzymatic glucose sensors [50] and DNA biosensors [51,52]. For example, tip-coated diamond nanowires with nickel nanoparticles were applied as a three- dimensional electrode for non-enzymatic oxidation of glucose in alkaline solution. The glucose oxidation potential was $110 \mathrm{mV}$ lower and the oxidation current was 30 times higher than those on a bare diamond electrode [36]. The oxidation current was proportional to the concentration of glucose in the range of $10 \mu \mathrm{M}$ to 1 $\mathrm{mM}$. The high current and low oxidation potential were attribute to a large electrode area of diamond nanowires, a three-dimensional effect, electrocatalytic ability of Ni nanoparticles, and changed mass transport on this electrode [36]. More specifically, this sluggish glucose oxidation was kinetically-controlled and thus sensitive to nanoscopic surface area of the electrode. Bigger electrode area led to higher Faradaic current. Moreover, glucose approached 
three-dimensionally to the electrode, resulting in larger active/contact areas for its oxidation. Furthermore, catalytic ability of Ni nanoparticles, more precisely oxidized Ni nanoparticles accelerated such an oxidation process [36].

Tip-functionalized diamond nanotextures were employed to bond single-strand DNA (ss DNA) (Figure 8), leading to well-defined spaces between ss DNA as well as the stable C-C bonds between the linkers and ss DNA. With aid of negatively charged redox indicators, voltammetric detection of DNA hybridization was realized with a detection limit of about 2 pM on $0.03 \mathrm{~cm}^{2}$ sensor area for more than 30 hybridization/denaturation cycles. The discrimination of single-base mismatched complementary DNA was achieved as well $[51,52]$. It was suggested the detection limit can be further improve via miniaturization of the sensor area (e.g., by use of ultramicroelectrodes and NEAs, etc.). Such kind of DNA biosensors are pretty promising for real device applied in clinical environments where high though-put is required on a $24 \mathrm{~h}$ per day basis.

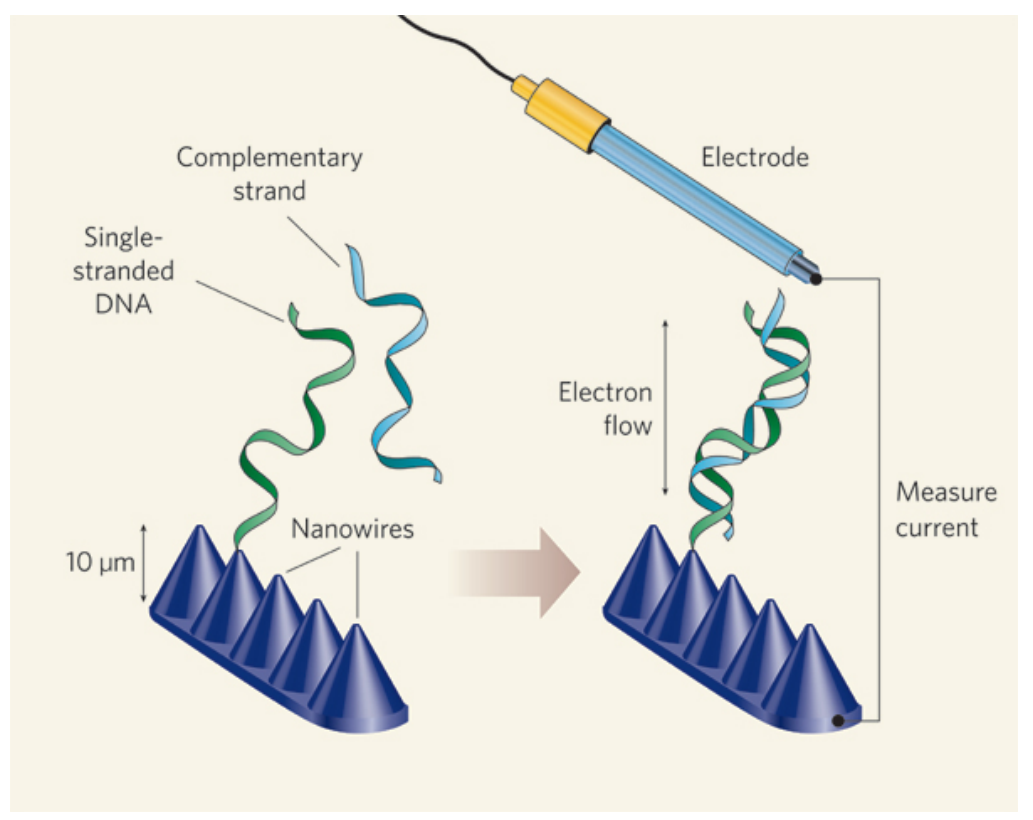

Figure 8. DNA sensing on diamond nanowires. DNA biosensors have been fabricated by attaching ss DNA to diamond nanowires that have been constructed on a diamond surface. Both DNA and diamond conduct electricity, so electrons from the diamond substrate flow along the DNA. The conductivity of the system changes when complementary strands of DNA bind to the tethered DNA. This effect has been quantified by immersing the diamond sensor in a solution of DNA, placing an electrode close to the diamond surface and measuring the current that flows between them. (Reproduced with permission from Ref. [167] Copyright 2008, Nature Publisher) 
Diamond nanowires based immunosensors have been reported [48,49,53]. For instance, boron-doped diamond nanowires coated with a conducting polymer, poly[3(pyrrolyl)carboxylic acid] (PPA), was used for the site-specific immobilization of histidinetagged peptides after its chelation with copper ions (Figure 9). The binding process measured using electrochemical impedance spectroscopy confirmed that the peptide loading capability is comparable to those of commercially available interfaces [53]. The charge transfer resistance of $\mathrm{Cu}^{2+}$ coordinated PPA-nanowires was rather sensitive to the concentrations of His-tapped peptides as low as $10 \mathrm{nM}$, at least 10 times lower on a planar diamond electrode modified with PPA and chelated with $\mathrm{Cu}^{2+}$. According to the Langmuir adsorption isotherm, the calculated affinity constant $\left(K_{\mathrm{A}}\right)$ of His-Tag-des-Arg-bradykinin peptide to $\mathrm{Cu}^{2+}$ coordinated PPA-nanowires was as $K_{\mathrm{A}}=(1.15 \pm 0.5) \times 10^{6} \mathrm{M}^{-1}$, which was comparable to the values obtained using surface plasmon resonance. Wile for PPA-nanowires $K_{\mathrm{A}}=(0.31$ $\pm 0.5) \times 10^{6} \mathrm{M}^{-1}$ was much lower. Such an interface was easily regenerated several times using ethylenediaminetetraacetic acid. It was stated further that the strategy developed in this work can be easily extended to other His-tagged biomolecules for studying biomolecular interactions.

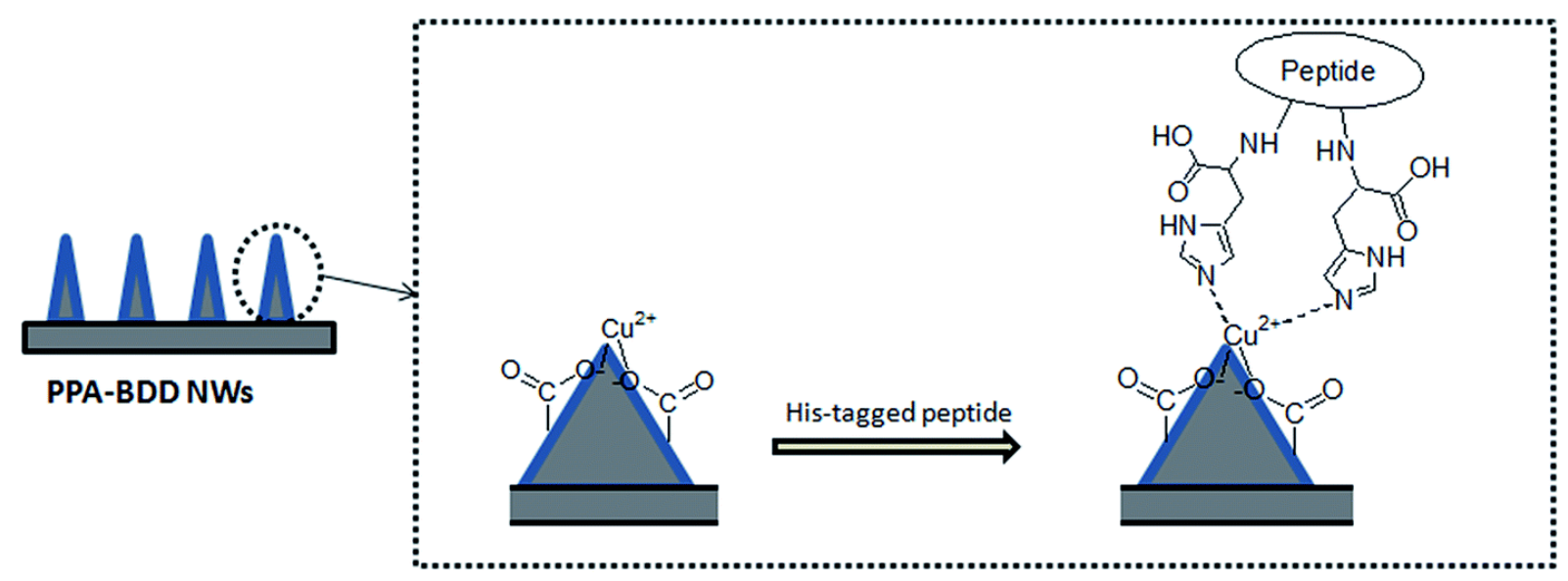

Figure 9. Immunosensors using diamond nanowires. Schematic illustration of His-tagged peptide interaction with the $\mathrm{Cu}^{2+}$ terminated polymer-diamond nanowire interface (PPA-BDD NWs). (Reproduced with permission from Ref. [53], Published by The Royal Society of Chemistry)

\subsubsection{Diamond nanoparticles}

Detonation diamond nanoparticles have shown increased electrical conductivities, probably due to their large specific surface area and large numbers of surface defects as well as their cluster structures. Therefore they have been employed as a novel type of electrode material to 
develop electrochemical sensors for the detection of azathioprine [93], epinephrine and uric acid in the presence of ascorbic acid [94], tryptophan, 5-hydroxytryptophan [96], and nitrite $[95,99]$. The matrix of diamond and silver nanoparticles were applied for electrochemical monitoring of thioridazine [97] and hydrogen peroxide [98]. Synergistic effect of two kinds of nanoparticles was proposed to demonstrate the satisfactory electrochemical activity. The performance of some reported sensors is listed in Table 1.

Diamond nanoparticles based electrochemical biosensors have been reported as well (Table 1). Glucose oxide, cyt c, hemoglobin, horseradish peroxidase, alcohol dehydrogenase, and lactate oxidase have been immobilized on diamond nanoparticles for the detection of glucose [100-104], alcohols [105], and lactate [106], respectively. For example, alcohol dehydrogenase (ADH), non-covalently immobilized/adsorbed on oxidized diamond nanoparticles, has been estimated with Langmuir isotherms. The amout of adsorbed ADH was dependent on $\mathrm{pH}$ values of the solutions. A higher packing density of ADH was achieved at its isoelectric point. Its relative activity was retained up to $70 \%$ under optimum $\mathrm{pH}$ conditions. An ethanol bioelectrochemical cell and an alcohol biosensor were then proposed [105]. Antibody immobilization was reported on diamond nanoparticles seeded interdigitated electrodes (IDEs). Such an impedance biosensor improved overall detection sensitivity, namely the resistance to charge transfer. The sensor performance was better than those based on gold or ITO electrodes. When sensing bacteria from $106 \mathrm{cfu} \mathrm{mL}^{-1} \mathrm{E}$. coli O157:H7, the resistance to charge transfer at the IDEs decreased by 38.8\%, which was nearly 1.5 times better than that reported previously using redox probes. In the case of $108 \mathrm{cfu} \mathrm{mL} \mathrm{m}^{-1} \mathrm{E}$. coli $\mathrm{O} 157: \mathrm{H7}$, the charge transfer resistance was changed by 46\% [107]. By coating borondoped diamond nanoparticles with $\mathrm{Ni}(\mathrm{OH})_{2}$, non-enzymatic glucose sensor was constructed. The detection limit was 1.2 $\mu \mathrm{M}$ [150]. Recently, boron-doped diamond nanoparticles have been electrostatically self-assembled on carbon nanotubes. Such a 3D network showed a low electron transfer resistance but a large effective surface area, resulted in an improved electrochemical performance in glucose detection [152].

\subsection{Electrochemical energy storage}

Diamond nanostructures and particles have been utilized for energy storage and related applications. Due to wide electrochemical potential window (e.g., ca. $2.5 \mathrm{~V}$ in aqueous electrolytes and $7.3 \mathrm{~V}$ in organic electrolytes [57-61]), enhanced surface area, as well as high stability, diamond nanostructures have been employed as the electrode materials for 
constructing electrochemical capacitors (e.g., electric double layer capacitors (EDLC), pseudocapacitors), lithium batteries, and dye-sensitive solar cells. Diamond nanoparticles have been applied extensively as the support to load metal catalysts for electrocatalytic reactions.

\subsubsection{Electrochemical capacitors}

\subsubsection{Diamond nanostructures}

Diamond nanowires have been used for the construction of EDLCs [59-70]. For example, diamond honeycomb nanostructures based EDLCs showed a capacitance of $3910 \mu \mathrm{F} \mathrm{cm}{ }^{-2}$ and $666 \mu \mathrm{F} \mathrm{cm} \mathrm{cm}^{-2}$ in aqueous and organic solution, respectively [59-61]. Silicon nanowires coated with a thin diamond film (240 nm in thickness) showed a capacitance of $105 \mu \mathrm{F} \mathrm{cm} \mathrm{cm}^{-2}$ in a mixture of propylene carbonate with 1-methyl-1-propyl pyrrolidinium bis(trifluoromethylsulfonyl)imide, one room temperature ionic liquid. A high energy density of $84 \mu \mathrm{J} \mathrm{cm}^{-2}$, a power density of $0.94 \mathrm{~mW} \mathrm{~cm}{ }^{-2}$, a series resistance of $206 \Omega$, and good stability (retention stability of $93.3 \%$ after 10,000 cycles at a scan rate of $5 \mathrm{~V} \mathrm{~s}^{-1}$ ) were shown [65]. The areal capacitance of diamond EDLCs was recently enhanced to the " $\mathrm{mF} \mathrm{cm}^{-2}$ " range by use of diamond nanostructures, so-called diamond papers. The prototype pouch-cell supercapacitor showed a gravimetric capacitance of $0.688 \mathrm{mF} \mathrm{cm}{ }^{-2}\left(0.645 \mathrm{~F} \mathrm{~g}^{-1}\right)$ per paper layer in aqueous electrolyte, a relaxation time of $10-100 \mathrm{~ms}$, a series resistance of $1.3 \Omega$, the specific power of $1 \times 10^{5} \mathrm{~W} \mathrm{~kg}^{-1}$, and a capacitance retention of $92 \%$ during 20000 cycles at 1 $\mathrm{mA} \mathrm{cm}{ }^{-2}$ [66]. Figure 10 shows the related performance of such a capacitor. On carbon felt coated with nanocrystalline diamond, a double layer capacitance of $2.6 \mathrm{mF} \mathrm{cm} \mathrm{cm}^{-2}$ and rectangular-shaped $\mathrm{CV}$ curves were obtained in $0.5 \mathrm{M} \mathrm{H}_{2} \mathrm{SO}_{4}$ at a scan rate of $0.1 \mathrm{~V} \mathrm{~s}^{-1}$ [67]. Carbonization of diamond films grown on carbon fibers at $2000{ }^{\circ} \mathrm{C}$ led to an increased

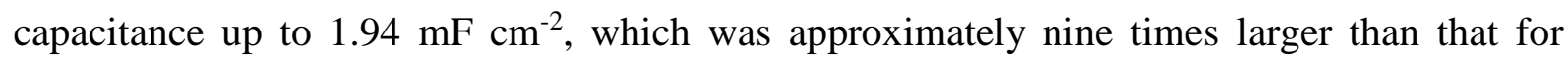
carbon fibers treated individually under identified conditions [68]. On $\mathrm{TiO}_{2}$ nanotubes coated with boron-doped diamond (200-500 nm in thickness), the specific capacitance was dependent on the boron concentration. In $0.1 \mathrm{M} \mathrm{NaNO}_{3}$, the specific capacitance of 2.10, 4.79, and $7.46 \mathrm{mF} \mathrm{cm}^{-2}$ was obtained at a scan rate of $0.01 \mathrm{~V} \mathrm{~s}^{-1}$ for a $[\mathrm{B}] /[\mathrm{C}]$ ratio of 2000, 5000 and 10 000, respectively. The substantial improvement of electrochemical performance and the excellent rate capability was explained with the synergistic effect of $\mathrm{TiO}_{2}$ treatment in $\mathrm{CH}_{4}: \mathrm{H}_{2}$ plasma and the high electrical conductivity of boron-doped diamond layers [69]. 

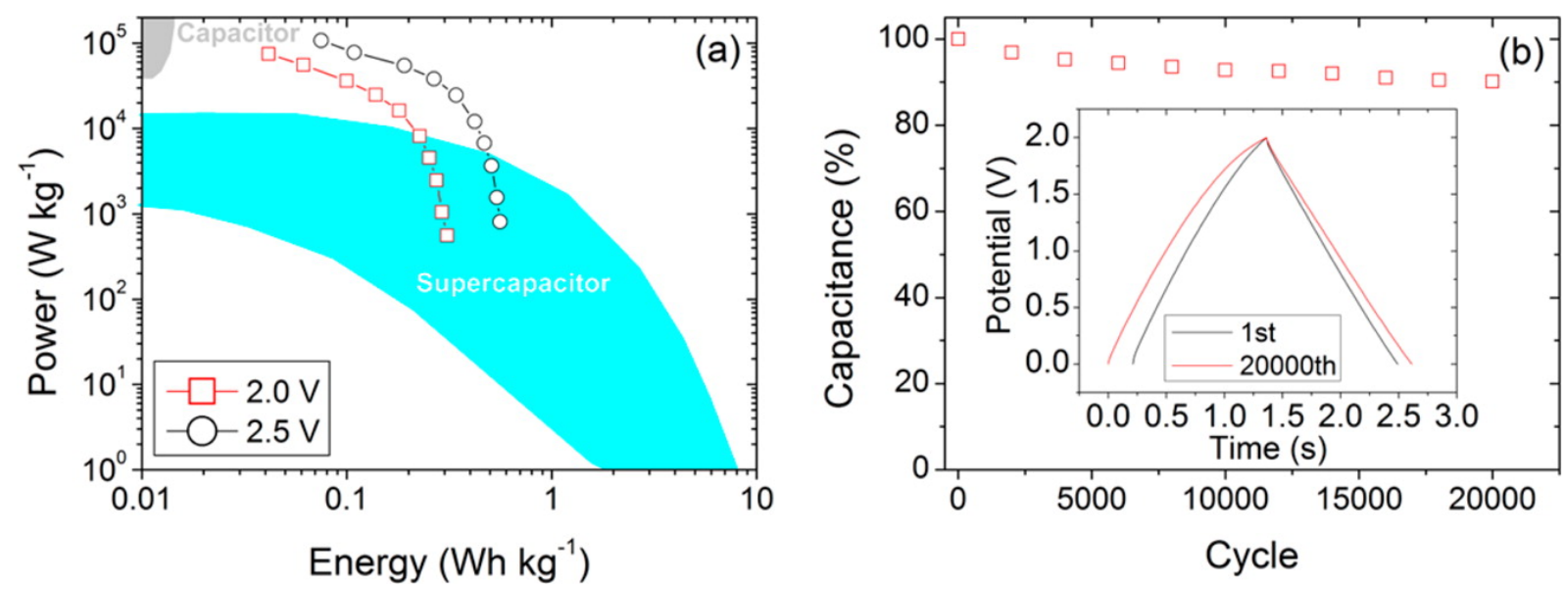

Figure 10. Performance of diamond paper based supercapacitors. (a) Ragone plot of the pouch cell working at 2.0 and $2.5 \mathrm{~V}$ potential windows; the colored region shows the typical performance of traditional and other supercapacitor performance; (b) the capacitance retention during the 20000-cycle galvanostatic charging-discharging test at $1 \mathrm{~mA} \mathrm{~cm}{ }^{-2}$; inset shows the first and the last cycle. (Reproduced with permission from Ref. [66], Copyright 2015, ACS Publisher.)

Porous diamond has been applied for EDLCs [71-73]. For example, porous conductive borondoped diamond membrane, fabricated with a two-step thermal treatment method, exhibited a double-layer capacitance of ca. $140 \mu \mathrm{F} \mathrm{cm}{ }^{-2}$ in an aqueous electrolyte, estimated from cyclic voltammetry and galvanostatic measurements [72]. Porous boron-doped diamond film, overgrown on carbon nanotubes, showed c.a. 450 times greater electroactive area and doublelayer capacitance than an equivalent flat boron-doped diamond electrode [71]. Another kind of porous diamond, formed on a highly porous polypyrrole scaffold, showed a capacitance up to $3 \mathrm{mF} \mathrm{cm}^{-2}$ in aqueous $\mathrm{LiClO}_{4}$ solution. For a hybrid electrode with an area of $0.12 \mathrm{~cm}^{-2}$, the series resistance was $20 \Omega$ at high frequencies. At a frequency of $1 \mathrm{~Hz}$, the series resistance increased to $400 \Omega$, which was still 600 times lower than that for a flat diamond [73]. A diamond network with a porosity from 15 to $68 \%$ led to hundreds of times enhancement of surface areas than that of flat diamonds (e.g., 490-fold for a $3 \mu \mathrm{m}$ thick diamond network). In $0.1 \mathrm{M} \mathrm{H}_{2} \mathrm{SO}_{4}$, the calculated double-layer capacitance of diamond network was $13.7 \mathrm{~F} \mathrm{~g}^{-1}$ or $17.3 \mathrm{~F} \mathrm{~cm}^{-3}$ at a scan rate of $0.1 \mathrm{~V} \mathrm{~s}^{-1}$, which is comparable to that (c.a. $13 \mathrm{~F} \mathrm{~g}^{-1}$ ) of a borondoped diamond hollow fiber [63]. Diamond foam based EDLCs attained specific capacitances of 598 and $436 \mu \mathrm{F} \mathrm{cm}^{-2}$ in aqueous and organic solutions, respectively. A high power density of $807 \mathrm{~W} \mathrm{~cm}{ }^{-3}$ was achieved, which touched the best power performance of electrolytic capacitors [62]. 
Recently diamond nanowires have been coated with pseudo-active species, nickel hydroxide, to fabricate pseudocapacitors. Such a pseduocapacitor showed a gravitational capacitance of $1601 \mathrm{~F} \mathrm{~g}^{-1}$ (about $80 \%$ of the theoretical value), a power density of up to $3 \times 10^{5} \mathrm{~W} \mathrm{~kg}^{-1}$, the electrode relaxation times of $1-20 \mathrm{~ms}$, and a capacitance loss of $44 \%$ from 0.005 to $1 \mathrm{~V} \mathrm{~s}^{-1}$. This high power density was explained by fast ion diffusion inside the three-dimensional composite [70].

\subsubsection{Diamond nanoparticles}

For supercapacitors, diamond nanoparticles were always thermally annealed at temperature above $1000{ }^{\circ} \mathrm{C}$. Due to the generation of carbon onions, energy is possible to be stored under a high current density and a high capacitance. For example, Gogotsi et al. investigated and compared in organic and aqueous electrolytes the performance of EDLCs based on carbon onions, diamond nanoparticles, carbon black and multi-walled carbon nanotubes [129]. Different methods were applied, including galvanostatic cycling measurements, electrochemical impedance spectroscopy and cyclic voltammetry. The capacitance of these EDLCs was dependent on the graphitization degree of diamond nanoparticle and the defects on the surface of these particles/tubes. The capacitances of $20-40 \mathrm{~F} \mathrm{~g}^{-1}$ and $70-100 \mathrm{~F} \mathrm{~g}^{-1}$ were achieved in $1 \mathrm{M} \mathrm{H}_{2} \mathrm{SO}_{4}$ and $6 \mathrm{M} \mathrm{KOH}$, respectively [129-131]. Recently a composite of reduced graphene oxide and diamond nanoparticles showed a capacitance of $186 \pm 10 \mathrm{~F} \mathrm{~g}^{-1}$ in $1.0 \mathrm{M} \mathrm{H}_{2} \mathrm{SO}_{4}$ and a stable capacitance retention [137].

To construct pseudocapacitors, diamond nanoparticles, actually in most cases carbon onions, were coated with pseudo-active species (e.g., $\mathrm{RuO}_{2}$ [151], phosphomolybdate [134] and polyaniline [135,136], etc.). For example, carbon onions and phosphomolybdate based pseudocapacitor exhibited a $20 \%$ increase in the capacitance, up to $600 \mathrm{mF} \mathrm{cm}^{-2}$ at $5 \mathrm{~V} \mathrm{~s}^{-1}$ [134]. Polyaniline was produced on diamond nanoparticles (or carbon onions) via either electropolymerization in a cavity electrode or a chemical oxidation method [136]. The pseudocapacitance of this electrode in $1.0 \mathrm{M} \mathrm{H}_{2} \mathrm{SO}_{4}$ electrolyte increased to $640 \mathrm{~F} \mathrm{~g}^{-1}$ when the weight ratio of diamond nanoparticles and polyaniline varied in the range of 3-28\%. This capacitance was 3-4 times higher than that of the activated carbons and more than 15 times higher than that of diamond nanoparticles and carbon onions. This high capacitance was explained by the porous network structure of this electrode. Moreover the charge-discharge characteristics were stable for 10000 charging/discharging cycles [136]. 


\subsubsection{Other energy storage devices}

Diamond nanostructures and particles have been tried for the construction of lithium batteries $[138,139]$ and fuel cells [43]. For example, functionalized detonation diamond nanoparticles and carbon onions have been applied as cathodes in Li-ion batteries [139]. A volumetric capacity of less than $23 \mathrm{~m} \mathrm{Ah} \mathrm{cm}^{-3}$ was shown, although it was much lower than 450-700 mA $\mathrm{h} \mathrm{cm}^{-3}$ offered by state-of-the-art high-density cathodes used in commercial Li-ion batteries [139]. The composite system of polyaniline and diamond nanoparticles prepared via electrochemical polymerization techniques was applied toward the iodine/iodide redox couple for the construction of dye-sensitised solar cells [140].

Diamond nanograss has been suggested as a potential anode for the construction of high performance methanol fuel cells [43]. Due to good biocompatibility of diamond, diamond nanograss could be employed as a conducting bridge between the redox center of outer membrane decaheme c-type cytochromes (OM c-Cyts) in its native structure and the electrode surface. Shorter electron-transfer distance and promoted direct electron transfer rate are expected. For example, enhanced electron transfer from OM c-Cyts of shewanella loihica PV4, a dissimilatory metal reducing bacterium, to boron-doped diamond nanograss based electrode was reopted (Figure 11). The addition of sodium lactate led to appreance of a pair of well defined redox waves on both a flat diamond and diamond nanograss, while no waves appeared without sodium lactate or the cells. It was concluded that a cellular sodium lactate oxidation process mediated by the OM c-Cyts. On the polarized flat diamond electrode for 25 $\mathrm{h}$, the sharp reduction peak at $-0.367 \mathrm{~V}$ (vs. $\mathrm{Ag} / \mathrm{AgCl}$ ) and the broad oxidation peak at 0.053 $\mathrm{V}$ (vs. $\mathrm{Ag} / \mathrm{AgCl}$ ) were ascribed to the irreversible electrochemistry of OM c-Cyts and sluggish heterogeneous electron transfer of OM c-Cyts. Such an electrode reaction was however quasireversible on diamond nanograss. The reversibility of electrochemistry of OM c-Cyts thus depended on the nanostructure of diamond electrode. An oxidation peak at $-0.052 \mathrm{~V}$ (vs. $\mathrm{Ag} / \mathrm{AgCl}$ ) and a reduction peak at $-0.422 \mathrm{~V}$ (vs. $\mathrm{Ag} / \mathrm{AgCl}$ ) were noticed. From the result of the linear relationship in logarithmic scales btween the peak currents and scan rates, this reaction was confirmed to be a mixed diffusion-adsorption controlled electrode process, or a complex combination of catalytic and substrate diffusion processes in the whole cell electrochemical system. 


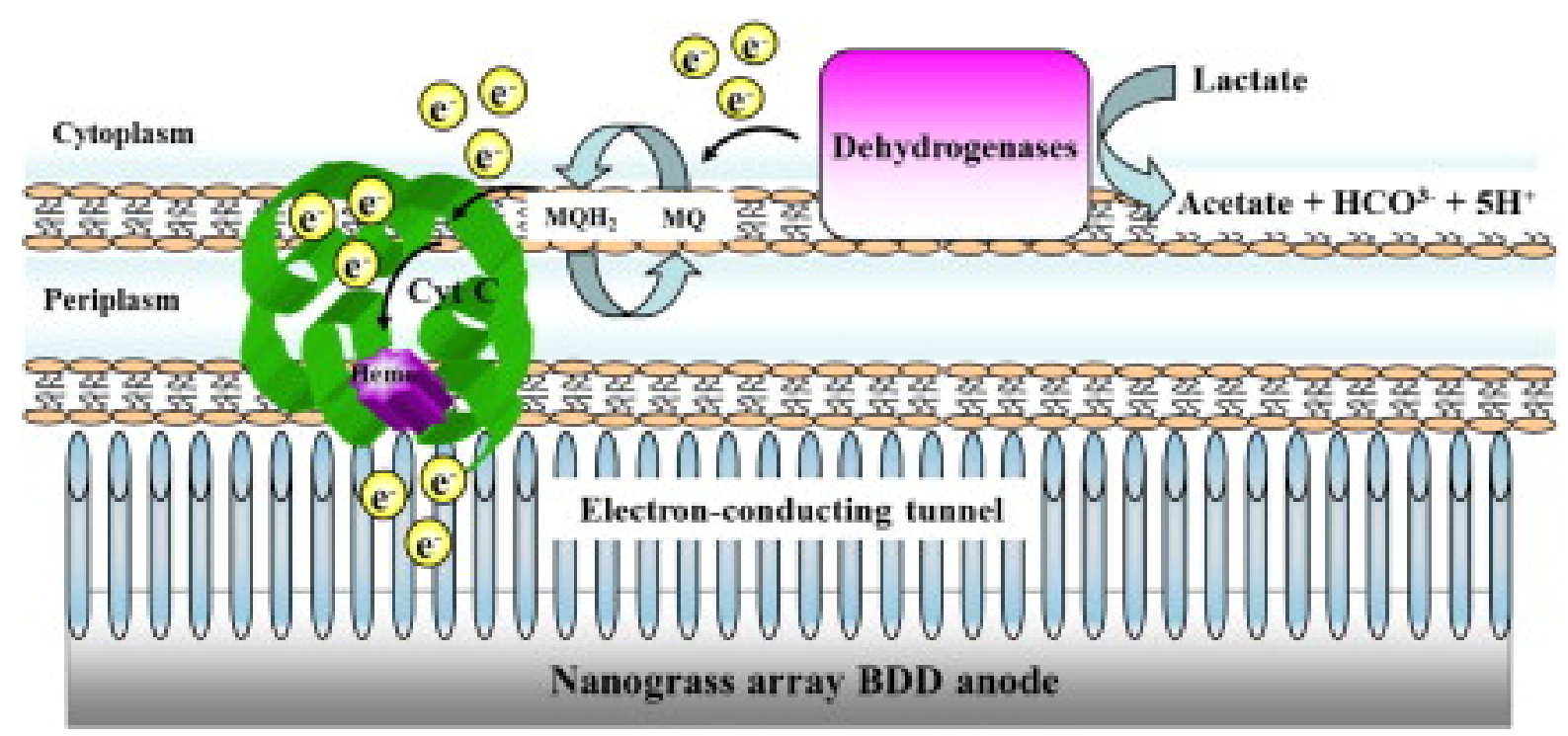

Figure 11. Enhanced direct electron transfer on diamond nanograss. Schematic demonstration of an enhanced electron transfer from outer membrane c-type cytochromes of shewanella loihica PV-4 to boron-doped diamond nanograss based electrode. (Reproduced with permission from Ref. [43] Copyright 2011, Elsevier).

\subsection{Electrocatalysts}

\subsubsection{Diamond nanostructures}

Tip-coated diamond nanowires with nickel nanoparticles were applied as a three-dimensional electrode for electrocatalytic hydrogen evolution [36]. In $0.1 \mathrm{M} \mathrm{H}_{2} \mathrm{SO}_{4}$, the onset potential for hydrogen evolution was the lowest (-0.2 Vvs. $\mathrm{Ag} / \mathrm{AgCl})$ on this three-dimensional electrode when the current density was higher than $-0.3 \mathrm{~mA} \mathrm{~cm}^{-2}$ at a scan rate of $0.10 \mathrm{~V} \mathrm{~s}^{-1}$. The variation of onset potentials from alkaline, neutral, to acidic solutions were due to the changed concentrations of protons. The Volmer-Tafel mechanism was employed to analyze such a phenomenon. On this three-dimensional electrode, the Tafel slope of $380 \mathrm{mV} \mathrm{dec}^{-1}$ in the potential range of -1.2 to $-1.4 \mathrm{~V}$ (vs. $\mathrm{Ag} / \mathrm{AgCl}$ ) was much higher than the theoretical value of $120 \mathrm{mV} \mathrm{dec}^{-1}$ on a flat diamond electrode. The high Tafel slope was assigned to oxides/hydro-oxides on diamond, a potential drop in the space charge layer of diamond electrode, and/or the accumulation of gas bubbles on the electrode surface, leading to a reduction of electrode area and to an increase of ohmic resistance. Moreover, due to bubbles formation at active nucleation sites, a rough surface haa more pronounced effect on the Tafel slope than a smooth electrode. Ni nanoparticles at the tip of diamond nanowires showed a long life-time [36]. However, it has been pointed out as well such an electrocatalytic reaction might not be true because such a three-dimensional electrode could behavior similarly as a porous electrode. The reduced overpotentials and much enhanced currents then reflected the 
porosity of the electrode and the changed mass transport between a porous electrode (nanowires based electrode) and semi-infinite diffusion.

Pt decorated diamond nanopits and nanorods have been applied for electrocatalytic oxidation of methanol [50]. The method of fabrication of such electrodes involved the electrodeposition of Pt particles on the diamond electrode surface, after which the structure was treated with either an oxygen plasma or an hydrogen plasma. In the former treatment, the Pt particles served as a hard resist during the oxygen plasma etching of the diamond, yielding structures consisting of Pt particles located on the top of diamond nanorods. In the latter treatment, the Pt catalysed gasification of diamond in the hydrogen plasma occurs, leading to the localisation of the Pt particles in nanopits on the electrode interface. It was shown that the hydrogen plasma treatment provided a viable route for the preparation of $\mathrm{Pt}$ decorated electrodes with significantly improved chemical stability [50].

Diamond nanowires have been coated with a thin Pt layer (1-3 nm) via DC sputtering to study catalytic oxygen/hydrogen adsorption/desorption reactions [77]. The active surface area of such a Pt-shell/diamond-nanowire-core electrode was 23 and 4.3 times higher than that for a planar Pt electrode and a diamond electrode coated with Pt nanoparticles via electrodeposition, respectively. This surface was stable even after 1000 full surface oxidation and reduction cycles [77].

Diamond nanostructures decorated locally (e.g., at the very tip) or fully with metal nanoparticles have been proved to be a novel electrode to investigate electrocatalytic oxidation and reduction reactions. This three-dimensional electrode showed advantages of larger surface area due to surface nanostructuring, high efficiency due to three-dimensional possibility for analytes to reactwith the electrode, long stability of metal catalysts due to the formation of metal carbide, and high chemical stability of working electrode in harsh environments ranging from acidic to alkaline media.

\subsubsection{Diamond particles}

Diamond nanoparticles have been used frequently as the support to load metal catalysts (e.g., Pt [108-114], Ni[115,116], Ti [117], Pd [118], Pt/Ni [119], Pt/Ru [120-123], Sn/Pb [124], $\mathrm{PtEu}[112,120]$ ) and other catalysts (e.g., $\mathrm{RuO}_{\mathrm{x}}$ [125], $\mathrm{TiO}_{2}$ [126] etc.). Different diamond nanoparticles have been used, including surface graphitized diamond nanoparticles with a 
diamond core covered by a graphitic carbon shell, bucky diamond nanoparticles with a nanoscale diamond core surrounded by a fullerene shell, and graphene coated diamond nanoparticles. Numerous approaches have been developed to load these catalysts on diamond nanoparticles, including electrodeposition [109,113], chemical reduction [114], and microwave-assisted polyol synthesis [112,120]. For example, electrodeposition of $\mathrm{Pt}$ nanoparticles on un-doped diamond nanoparticles (5-100 nm in diameter) was conducted in $1.1 \mathrm{mM}$ chloroplatinic acid solution. The electrodeposited Pt nanoparticles were welldispersed on the facet surfaces of diamond nanoparticles [109,128]. Pt and Ru nanoparticles were chemically deposited on undoped and boron-doped diamond nanoparticles by use of $\mathrm{NaBH}_{4}$ as the reduction agent and sodium dodecyl benzene sulfonate as the surfactant [114]. Microwave-assisted reduction method was used for the loading of catalysts of Pt [112], Pt/Ni [119], and Pt/Ru [123] to diamond nanoparticles. A microwave heating polyol method was used to prepare the PtRu electrocatalyst supported by undoped diamond nanoparticles [123]. $\mathrm{Ru}$ was partly dissolved in the face-centred cubic Pt lattice. The PtRu nanoparticles were small and uniform with the size of 2-4 nm, and highly dispersed on the surface of diamond nanoparticles [123]. A simple ultrasonic treatment in the presence of diamond powders prior to electrodeposition improved spatial distribution and a higher Pt dispersion over the electrode. A two-step method was reported to modify diamond nanoparticles with $\mathrm{Pt}$ and $\mathrm{TiO}_{2}$ nanoparticles, namely first by a microwave hydrolysis method, and then electrodeposition of Pt nanoparticles [126].

Regarding the applications, the investigated reactions were electrocatalytic oxidation of methanol/formic acid/CO and electrocatalytic reduction of oxygen. For example, Fermin et al. [118] utilized for the first time Pd and HPHT diamond nanoparticles (500 nm in diameter) based electrocatalysts for the electrochemical stripping of $\mathrm{CO}$ and oxidation of formic acid in acid solutions (Figure 12). CO stripping was observed in the first scan (continuous black lines), while hydrogen adsorption/absorption responses were observed in the second scan (dashed red lines). The disappearance of the CO stripping peak on subsequent scans and the reappearance of hydrogen peaks at negative potentials indicated complete removal of CO in the first scan. Through comparing these facts with those on Pd/Vulcan and E-Tek, they concluded that the inherent electrocatalytic activity of Pd particles was exploited when supported on diamond nanoparticles. Regarding the catalytic oxidation of formic acid, lower currents were obtained on the electrocatalysts from Pd and diamond nanoparticles. They explained as a smaller affinity of formic acid to diamond surface as opposed to the more 
porous Vulcan substrate. Later the same group studied the electrocatalytic reactivity of $\mathrm{Pt}$ nanoparticles coated HPHT diamond particles towards the oxidation of adsorbed CO, methanol, and formic acid with differential electrochemical mass spectrometry [89]. Diamond nanoparticles with different surface terminations were used for these electrocatalytic oxidation reactions, leading to different oxidation mechanism [89].

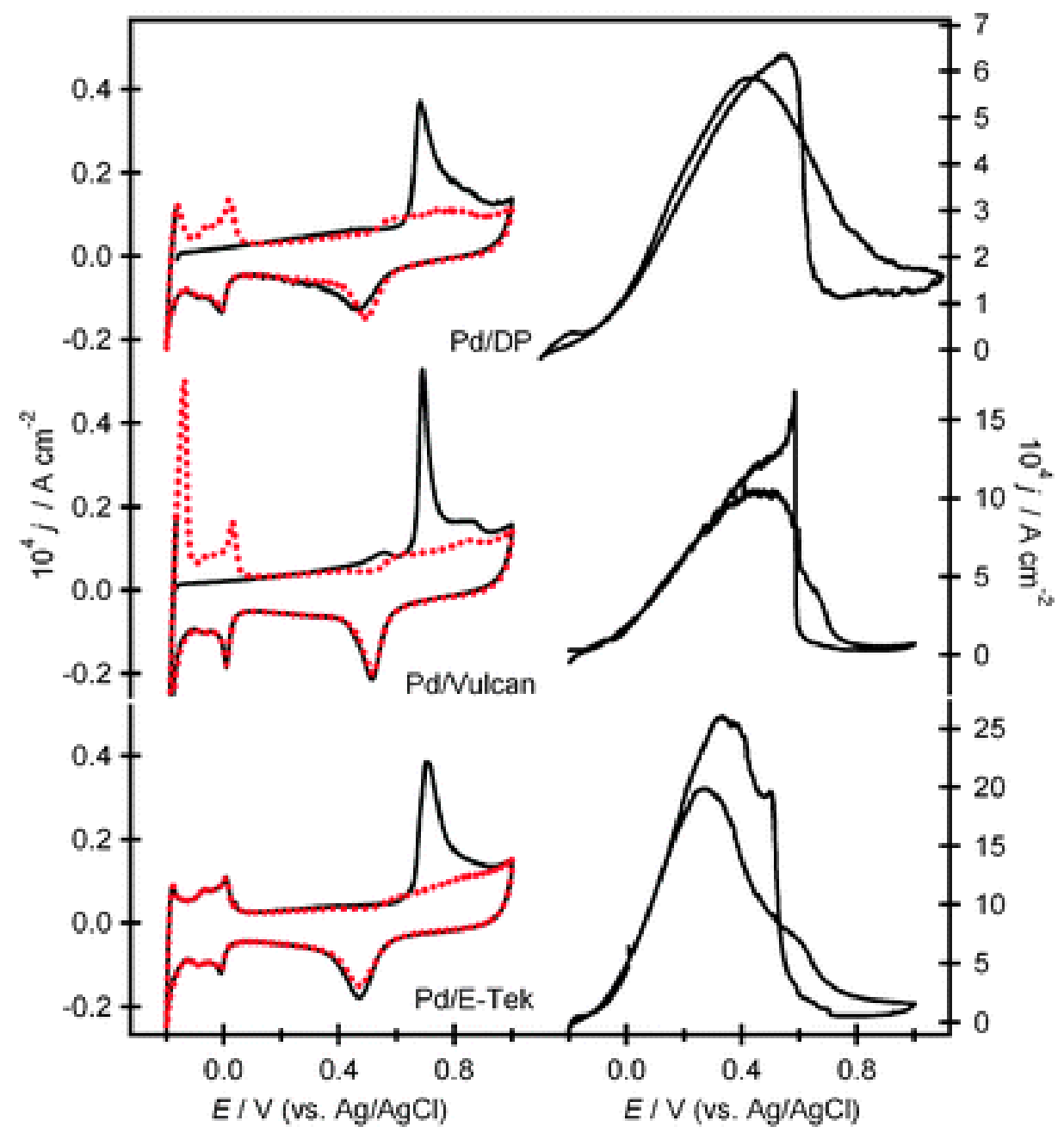

Figure 12. Electrochemical stripping of CO on Pd loaded diamond nanoparticles. cyclic voltammograms of (left) $\mathrm{CO}$ stripping in $0.5 \mathrm{M} \mathrm{H}_{2} \mathrm{SO}_{4}$ and (right) oxidation of $2 \mathrm{M}$ formic acid at a scan rate of $0.02 \mathrm{~V} \mathrm{~s}^{-1}$ using the electrocataysts of the Pd loaded diamond nanoparticles, Pd/Vulcan and E-Tek. (Reproduced with permission from Ref. [118], Published by The Royal Society of Chemistry)

Diamond nanoparticles with smaller diameters (e.g. $5 \mathrm{~nm}$ ) exhibited better electrocatalytic activity towards electrocatalytic oxidation of methanol than bigger ones (e.g. $100 \mathrm{~nm}$ ) $[109,128]$. In these studies, the surface of diamond nanoparticles were coated with electrodeposited Pt nanoparticles [109,128]. Application of these Pt modified diamond electrodes in the electrochemical oxidation of hydrogen peroxide was demonstrated [113]. 
The ink-paste method was used to prepare the membrane electrode assembly with Pt and $\mathrm{Pt}-\mathrm{Ru}$ modified undoped and boron-doped diamond nanoparticle catalytic systems. Their performances were examined in a direct methanol fuel cell system [121]. PtRu catalyst exhibited higher activity and stability for methanol electro oxidation reaction than individual Pt catalyst [123]. In acid medium the $\mathrm{Pt} / \mathrm{TiO}_{2}$ catalyst system possessed higher electrocatalytic activity for methanol oxidation reaction compared with the individual Pt catalyst [117]. Electrocatalytic oxidation of methanol was tested on the composite based on boron-doped diamond particles (500 $\mathrm{nm}$ and $5 \mu \mathrm{m}$ in diameter) and metallic oxides [149]. The investigation of electrocatalytic reduction of oxygen on metal catalysts coated diamond nanoparticles has been conducted using cyclic voltammetry, chronoamperometry and linear sweep voltammetry [119]. The Pt/Ni catalysts exhibited better electrocatalytic activities than the Pt catalysts either for methanol oxidation reaction or for oxygen reduction reaction [119]. TiN coated diamond nanoparticles showed higher catalytic activity and better stability in methanol oxidation and oxygen reduction reactions compared with the individual catalysts on carbon and on diamond nanoparticles [127].

\subsection{Other applications}

Diamond nanostructures and nanoparticles have been proposed for other electrochemical applications [55,74-76]. For example, porous diamond membrane was applied as a filter to separate differently charged 5-carboxyfluorescein and substance P under different biases [75]. Diamond nanowires enhanced the intensity of electrogenerated chemiluminescence (ECL) of a ruthenium tris $\left(2,2^{\prime}\right)$ bipyridyl/tripropylamine system [55]. The enhancement of ECL intensity was attributed to the highly facile oxidation of tripropylamine on diamond nanowires, resulting from large surface area, improved electrocatalytic activity, and accelerated electron transfer of diamond nanowires. It was stated that this study revealed an effective method for the ultrasensitive detection of ruthenium tris $\left(2,2^{\prime}\right)$ bipyridyl and would help increase the efficiency of immunoassays and DNA analysis based on ruthenium tris(2,2')bipyridyl ECL.

Diamond NEAs have been applied to investigate surface-sensitive adsorption phenomena [155]. The adsorption of neutral methyl viologen $\left(\mathrm{MV}^{0}\right)$ was used as a model system (Figure 13). Diffusion-controlled processes manifested themselves as sigmoidal-shaped voltammograms on oxygen-terminated diamond NEAs, whereas adsorption-controlled processes resulted in peaks in the voltammogram for hydrogen-terminated diamond NEA. The change in the shapes of these voltammograms was due to the drastic changes that occur 
in the diffusion profiles during the transition. It altered from hemispherical diffusion on oxygen-terminated surface to thin layer electrochemistry upon adsorption on hydrogenterminated surface. In this way the de-convolution of diffusion-controlled current from adsorption-controlled current was conducted. By analysing anodic stripping process at high scan rates, the deposition of amorphous $\mathrm{MV}^{0}$ was approved on a hydrogen-terminated diamond NEAs. The types and the concentration of the buffer solutions were changed to alter the interaction/adsorption of neutral $\mathrm{MV}^{0}$ with/on the hydrogen terminated-electrode surface. For example, an increase of the concentrations of phosphate buffer (PB) and $\mathrm{KCl}$ solutions led to an enhancement of the anodic stripping peak current. The same impact was seen on the adsorption of $\mathrm{MV}^{0}$ on a hydrogen terminated diamond NEA when the concentrations of guanidine (Gnd) and urea solutions were reduced. Since the ions in phosphate buffer and and $\mathrm{KCl}$ solutions increased hydrophobic interactions, whereas the ions in guanidine and urea decreased hydrophobic interactions, the effect of ions on the interaction of $\mathrm{MV}^{0}$ and the hydrophobic diamond surface was correlated with the Hofmeister series. Subsequently, the adsorption of $\mathrm{MV}^{0}$ on a hydrogen terminated diamond NEA was controlled by hydrophobic interaction. Therefore diamond NEA is ideal for the study of adsorption phenomena at the liquid-solid interface in voltammetry.
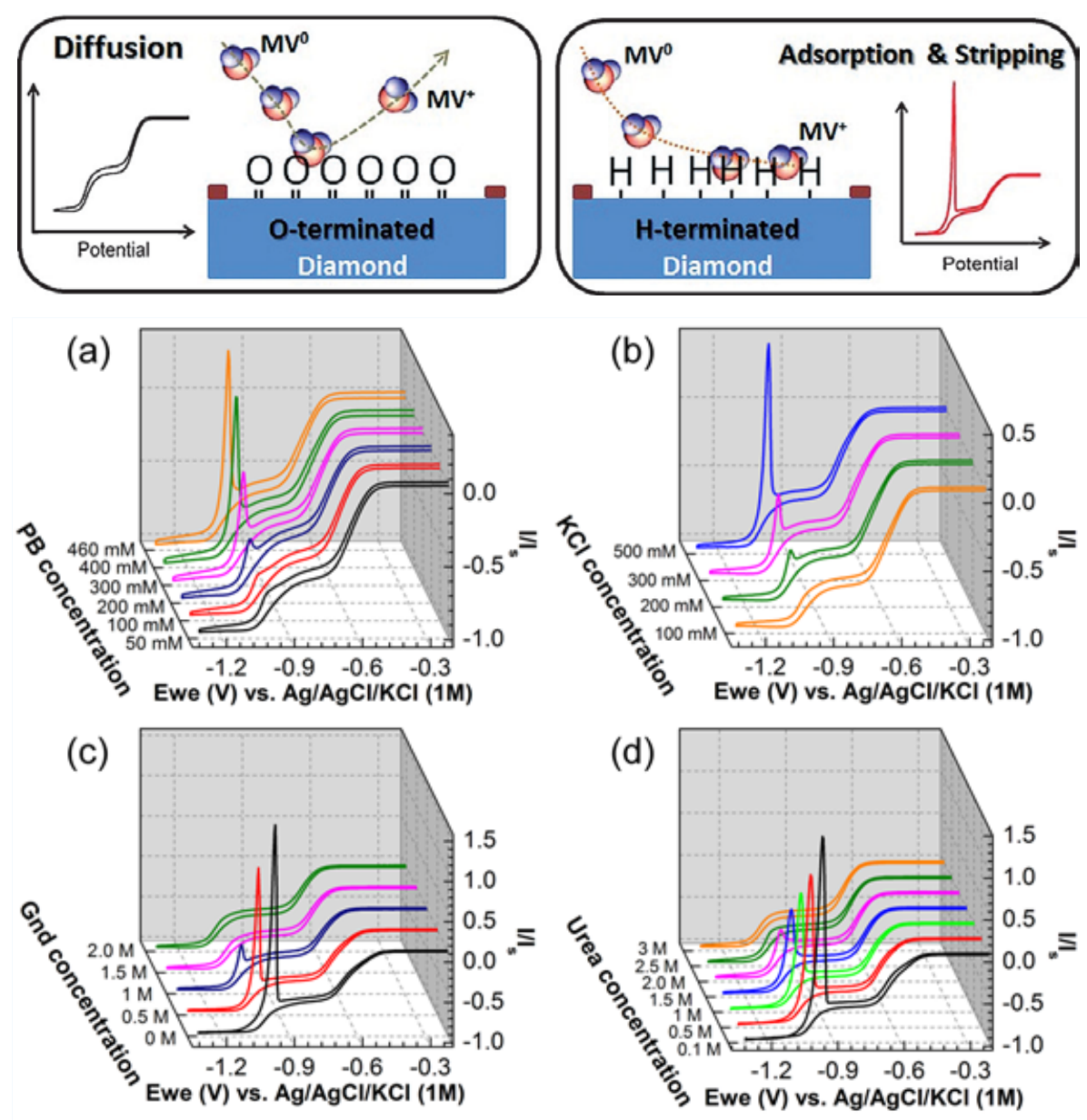
Figure 13. Detection of surface sensitive reactions on diaomnd NEAs. Schematic plots of voltammetric behavior of methyl viologen on hydrogen (left) and oxygen (right) terminated diamond NEAs. Cyclic voltammograms of $\mathrm{MV}^{2+}(0.4 \mathrm{mM})$ at a scan rate of $5 \mathrm{~V} \mathrm{~s}^{-1}$ in (a) phosphate buffer (PB) solution and (b) $\mathrm{KCl}$ solution with different concentrations. Cyclic voltammograms of $\mathrm{MV}^{2+}(1 \mathrm{~mm})$ in $\mathrm{KCl}(0.1 \mathrm{M})$ with increasing concentrations of (c) guanidine (Gnd) and (d) urea at a scan rate of $5 \mathrm{~V} \mathrm{~s}^{-1}$. The diamond NEA was hydrogenterminated. The currents were normalized to the steady state current of the reduction of $\mathrm{MV}^{+}$to $\mathrm{MV}^{0}$. (Reproduced with permission from Ref. [155], Copyright 2013, Wiley)

Diamond nanoparticles have been applied in corrosion inhibition [141], and as the metal-free catalysts for oxidant- and steam-free dehydrogenation [142]. For example, the nanocomposite of polyaniline and diamond nanoparticles showed an ohmic junction and wide potential values, independent of redox characteristics of both polyaniline and diamond nanoparticles. These excellent characteristics of corrosion inhibitor were explained by changed chain conformation and electronic properties, achieved by the interaction of the free electron pairs of the nitrogen atoms in the polyaniline with a charged molecule on the surface of diamond nanoparticles, [141]. Boron-doped diamond powder was applied as a stationary phase in electrochemically modulated liquid chromatography [153]. Boron-doped diamond powder based electrode was stable over a wide range of applied potential (e.g., -1.2 to $1.2 \mathrm{~V}$ vs. $\mathrm{Ag} / \mathrm{AgCl}$ ), for a long time (e.g., $1 \mathrm{~h}$ ), in acidic media (e.g., $0.5 \mathrm{M} \mathrm{H}_{2} \mathrm{SO}_{4}$ ), and at high voltage (e.g., $1.4 \mathrm{~V}$ vs. $\mathrm{Ag} / \mathrm{AgCl}$ ), and temperatures (e.g., $80{ }^{\circ} \mathrm{C}$ ) [148]. They were thus corrosion-resistant during anodic polarization. In contrast, glassy carbon powder polarized under identical conditions underwent significant microstructural degradation and corrosion [148].

\section{Summary and outlook}

Diamond electrochemistry when probed at the nanoscale through the use of diamond nanostructures, nanoparticles and nanoelectrodes, gives rise to the field of diamond nanoelectrochemistry, which has been the focus of much attention in recent years from both fundamental aspects and in practical applications (e.g., in the fields of electroanalysis, energy storage, and electrocatalysts, etc.). In such electrochemical systems, diamond nanostructures (e.g., textures, wires, particles, pores, nanoelectrodes etc.) and diamond nanoparticles are employed as the working electrode, instead of planar macroscopic diamond electrodes. Relatively few reports have to date have focussed on using such working electrodes for 
electrochemical sensing, electrocatalytic degradation of pollutants, and electrosynthesis of valued chemicals.

For diamond nanoelectrochemistry, a key issue from a fundamental viewpoint is still to understand how the physical, chemical and electronic properties of diamond nanostructures and particles affect their electrochemical responses in different electrolytes. Therefore further activities should focus on the effect of nanoscaled surface termination, ratio of graphite to diamond, surface defects, and morphology of diamond nanostructures on their electrochemical properties in the absence and presence of redox probes. For example, to draw a clearer picture for electrode reactions on diamond nanostructures based three-dimensional electrodes, one needs investigate in detail the effect of electrode dimensions (e.g., diameter, length, and density, etc.), surface termination of nanowires as well as metal nanoparticles (e.g., composition, shape, and size, etc.) on the redox currents and overpotentials for different reactions. Especially, conductivity of individual nanostructures and particles, their local capacitive behaviour and electrochemical activities need to be clarified. Strategies of fully wetting diamond nanostructures (e.g., long nanowires and deep diamond nanopores, etc.) and of forming stable particles based film electrodes are required. In addition to these, some promising research topics include investigation of fast electrode kinetics, adsorption and electrostatic effects on molecular interactions, as well as measurements in low electrolyte concentrations using these nanostructures and particles. Diamond nanoelectrodes and their arrays are extremely promising due to their more efficient mass transport, low and stable background current and controllable surface interactions. From technique viewpoint, the growth of large-size and high quality diamond films (e.g., low ratios of graphite to diamond, uniformed doping, etc.), the formation of single nanowires/nanopores, the combination of these nanostructures (e.g., diamond nanowires based diamond nanoelectrodes, diamond nanoparticles coated diamond nanoelectrodes) will enable further advantages of diamond nanoelectrochemistry to be realized, leading to more novel concepts and applications, which may not be possible with other kinds of electrode materials. Therefore future attention from a practical viewpoint should be paid to apply diamond nanostructures and particles for the development of novel sensors, construction of high performance energy storage devices, and establishment of new electrocatalytic systems, etc. Their uses in electrochemical sensing of endocrine-disrupting chemicals, electrocatalytic oxygen reduction, electrocatalytic degradation of pollutants, photoelectrocatalytic $\mathrm{CO}_{2}$ conversion, electrosynthesis of use chemicals, biomolecule detection and filtration, and supercapacitor construction are foreseen. 
Functionalizing these nanostructures and particles with stable and electroactive modifiers, doping them with dopants (e.g., $\mathrm{N}$ and other atoms) will be important for those applications. Single molecular detectio using a diamond nanopore under electric fields, high performance diamond supercapacitor using the diamond nanostructures composites and redox electrolytes, highly efficient electrocatalytic system for degradation of pollutants are expected.

In conclusion, progress and achievements on diamond electrochemistry at the nanoscale using diamond nanostructures, nanoparticles and nanoelectrodes have been summarized. Through the input from material scientists, chemists, physics, and engineers, new results in the fields of electrochemical properties and applications of diamond nanostructures and nanoparticles will be obtained in the coming years. By showing and comparing the results in the published literature, we believe this review will help the readers to know more how diamond nanoelectrochemistry started and judge where it should evolve to in the future.

\section{Acknowledgements}

The author (N.Y.) thanks the financial support from German Research Foundation (DFG) under the project (grant no. YA344/1-1).

\section{References}

[1] Iwaki M, Sato S, Takahashi K, Sakairi H. Electrical conductivity of nitrogen and argon implanted diamond. Nucl. Instrum. Methods in Phys. Res. 1983;209-210:11291133.

[2] Pleskov YV, Sakharova AY, Krotova MD, Bouilov LL, Spitsyn BV. Photoelectrochemical properties of semiconductor diamond. J. Electroanal. Chem. 1987;228:19-27.

[3] Nebel CE, Ristein J. (ed.) Thin-Film Diamond I. Elsevier, 2003.

[4] Nebel CE, Ristein J. (ed.) Thin-Film Diamond II. Elsevier, 2004.

[5] Yang N. (ed.) Novel Aspects of Diamond: From Growth to Applications. Springer, 2015. 
[6] Fujishima A, Einaga Y, Rao TN, Tryk DA(ed.). Diamond Electrochemistry, Elsevier, Tokyo, 2005.

[7] Brillas E, Martinez-Huitle CA (ed.) Synthetic Diamond Films: Preparation, Electrochemistry, Characterization, and Applications. Wiley, 2011

[8] Bartlett PN. Electrochemistry of Carbon Electrodes (Band 16) in Advances in Electrochemical Sciences and Engineering (Eds.: Richard C, Lipkowski J), WileyVCH, Weinheim, 2015.

[9] Kraft A. Doped diamond: a compact review on a new, versatile electrode material. Int. J. Electrochem. Sci., 2007;2:355-385.

[10] Einaga Y, Foord JS, Swain GM. Diamond electrodes: diversity and maturity. MRS Bulletin, 2014;39:525-532.

[11] Yang N, Swain GM, Jiang X. Nanocarbon electrochemistry and electroanalysis: current status and future perspectives. Electroanal. 2015, doi: 10.1002/elan.201500577.

[12] Garcia-Segura S, dos Santos EV, Martinez-Huitle CA. Role of $\mathrm{sp}^{3} / \mathrm{sp}^{2}$ ratio on the electrocatalytic properties of boron-doped diamond electrodes: a mini review. Electrochem. Commun., 2015;59:52-55.

[13] Einaga Y. Diamond electrodes for electrochemical analysis. J. Appl. Electrochem., 2010;40:1807-1816.

[14] Martinez-Huitle CA, Quiroz Alfaro MA. Recent environmental applications of diamond electrode: critical review. J. Environ. Eng. Manage. 2008;18:155-172.

[15] Panizza M, Brillas E, Comninellis C. Application of boron-doped diamond electrodes for wasterwater treatment. J. Environ. Eng. Manage. 2008;18:139-153.

[16] Comninellis C, Chen G (ed.) Electrochemistry for the Environment. Springer, 2011.

[17] Eguiluz KIB, Peralta-Hernandez JM, Hernandez-Ramirez A, Guzman-Mar JL, Hinojosa-Reyes L, Martınez-Huitle CA, Salazar-Banda GR. The use of diamond for energy conversion system applications: a review. Int. J. Electrochem. 2012;2012:675124. doi:10.1155/2012/675124.

[18] Waldvogel SR, Mentizi S, Kirste A. Boron-doped diamond electrodes for electroorganic chemistry. Top. Curr. Chem., 2012;320:1-31.

[19] Waldvogel SR, Elsler B. Electrochemical synthesis on boron-doped diamond, Electrochim. Acta 2012;82:434-443. 
[20] Radjenovic J, Sedlak DL. Challenges and opportunities for electrochemical processes as next generation technologies for the treatment of contaminated water. Environ. Sci. Technol. 2015;49:11292-11302 .

[21] Zhao G, Shen S, Li M, Wu M, Cao T, Li D. The mechanism and kinetics of ultrasound-enhanced electrochemical oxidation of phenol on boron-doped diamond and Pt electrodes. Chemosphere 2008;73:1407-1413.

[22] Liu L, Zhao G, Wu M, Geng R. Electrochemical degradation of chlorobenzene on boron-doped diamond and platinum electrodes. J. Hazard. Mater. 2009;168:179-186.

[23] Gao J, Zhao G, Shi W, Li D. Microwave activated electrochemical degradation of 2,4dichlorophenoxyacetic acid at boron-doped diamond electrode. Chemosphere 2009;75:519-525.

[24] Chai S, Zhao G, Zhang Y, Wang Y, Nong F, Li M, Li D. Selective photoelectrocatalytic degradation of recalcitrant contaminant driven by an n-p heterojunction nanoelectrode with molecular recognition ability. Environ. Sci. Technol. 2012;46:10182-10190.

[25] Yang N, Uetsuka H, Williams OA, Osawa E, Tokuda N, Nebel CE, Vertically aligned diamond nanowires: Fabrication, characterization, and application for DNA sensing. Phys. Stat. Sol. A 2009;206:2048-2056.

[26] Yang N, Smirnov W, Nebel CE. Diamond nanotextures: technologies, properties, and electrochemical applications in Applied Surface Chemistry of Nanomaterials, Chehimi M, Pinson J (ed.). NOVA Publisher, 2013, pp 33-54.

[27] Yu Y, Wu L, Zhi J. Diamond nanowires: fabrication, structure, properties, and applications. Angew. Chem. Int. Ed. 2014;53:14326-14351.

[28] Szunerits S, Coffinier Y, Boukherroub R. Diamond nanowires: a novel platform for electrochemistry and matrix-free mass spectrometry. Sensors 2015;15:12573-12593.

[29] Yang N, Uetsuka H, Osawa E, Nebel CE. Vertically aligned nanowires from borondoped diamond. Nano Letters 2008;8:3572-3576.

[30] Smirnov W, Kriele A, Yang N, Nebel CE. Aligned diamond nano-wires: fabrication and characterisation for advanced applications in bio and electrochemistry. Diam. Relat. Mater. 2009;18:186-189.

[31] Zou YS, Yang Y, Zhou YL, Li ZX, Yang H, He B, Bello I, Zhang WJ. Surface nanostructuring of boron-doped diamond films and their electrochemical performance, J. Nanosci. Nanotech. 2011;11:7914-7919. 
[32] Wei M, Terashima C, Lv M, Fujishima A, Gu Z-Z. Boron-doped diamond nanograss array for electrochemical sensors. Chem. Commun. 2009:3624-3626.

[33] Shalini J, Sankaran KJ, Dong CL, Lee CY, Tai NH, Lin IN. In situ detection of dopamine using nitrogen incorporated diamond nanowire electrode. Nanoscale 2013;5:1159-1167.

[34] Luo D, Wu L, Zhi J, Fabrication of boron-doped diamond nanorod forest electrodes and their application in nonenzymatic amperometric glucose sensing. ACS Nano 2009;3:2121-2128.

[35] Wang Q, Subramanian P, Li M, Yeap WS, Haenen K, Coffinier Y, Boukherroub R, Szunerits S. Non-enzymatic glucose sensing on long and short diamond nanowires electrodes. Electrochem. Commun. 2013;34:286-290.

[36] Yang N, Smirnov W, Nebel CE. Three-dimensional electrochemical reactions on tipcoated diamond nanowires with nickel nanoparticles. Electrochem. Commun. 2013;27:89-91.

[37] Szunerits S, Coffinier Y, Galopin E, Brenner J, Boukherroub R. Preparation of borondoped diamond nanowires and their application for sensitive electrochemical detection of tryptophan. Electrochem. Commun. 2010;12:438-441.

[38] Wang Q, Vasilescu A, Subramanian P, Vezeanu A, Andrei V, Coffinier Y, Li M, Boukherroub R, Szunerits S. Simultaneous electrochemical detection of tryptophan and tyrosine using boron-doped diamond and diamond nanowires electrodes. Electrochem. Commun. 2013;35:84-87.

[39] Lv M, Wei M, Rong F, Terashima C, Fujishima A, Gu Z-Z. Electrochemical detection of catechol based on as-grown and nanograss array boron-doped diamond electrodes. Electroanalysis 2010;22:199-203.

[40] Yang N, Hoffmann R, Smirnov W, Kriele A, Nebel CE. Interface properties of cytochrome c on nano-textured diamond surface. Diam. Relat. Mater. 2011;20:269273.

[41] Yang N, Smirnov W, Kriele A, Hoffmann R, Nebel CE. Nano-textured surface for enhanced protein redox activity. Phys. Status Solidi A 2010;207:2069-2072.

[42] Yang N, Hoffmann R, Wmirnov R, Kriele A, Nebel CE. Direct electrochemistry of cytochrome c on nano-textured diamond surface. Electrochem. Commun. 2010;12: 1218-1221. 
[43] Wu W, Bai L, Lin X, Tang Z, Gu Z-Z. Nanograss array boron-doped diamond electrode for enhanced electron transfer from Shewanella loihica PV-4. Electrochem. Commun. 2011;13:872-874.

[44] Wu W, Gu Z-Z, Liu X, Bai L, Tang Z. Nanograss array boron-doped diamond electrode for toxicity sensor with Shewanella loihica PV-4 in bioelectrochemical systems. Sensor Letters 2014;12:191-196.

[45] Hoffmann R, Kriele A, Kopta S, Smirnov W, Yang N, Nebel CE. Intentional adsorption of cytochrome c to diamond. Phys. Status Solidi A 2010;207:2073-2077.

[46] Hoffmann R, Kriele A, Obloh H, Tokuda N, Smirnov W, Yang N, Nebel CE. The creation of a biomimetic interface between boron-doped diamond and immobilized proteins. Biomaterials 2011;30:7325-7332.

[47] Hoffmann R, Obloh H, Tokuda N, Yang N, Nebel CE. Fractional surface termination of diamond by electrochemical oxidation. Langmuir 2012;28:47-50.

[48] Subramanian P, Foord J, Steinmueller D, Coffinier Y, Boukherroub R, Szunerits S. Diamond nanowires decorated with metallic nanoparticles: A novel electrical interface for the immobilization of histidinylated biomolecules. Electrochim. Acta 2013;110:48.

[49] Subramanian P, Motorina A, Yeap WS, Haenen K, Coffinier Y, Zaitsev V, Niedziolka-Jonsson J, Boukherroub R, Szunerits S. Impedimetric immunosensor based on diamond nanowires decorated with nickel nanoparticles. Analyst 2014;139:17261731.

[50] Shpilevaya I, Smirnov W, Hirsz S, Yang N, Nebel CE, Foord JS. Nanostructured diamond decorated with Pt particles: preparation and electrochemistry. RSC Adv. 2014;4:531-537.

[51] Yang N, Uetsuka H, Osawa E, Nebel CE. Vertically aligned diamond nanowires for DNA sensing. Angew. Chem. Int. Ed. 2008;47:5183-5185.

[52] Yang N, Uetsuka H, Nebel CE. Biofunctionalization of vertically aligned diamond nanowires. Adv. Funct. Mater. 2009;19:887-893.

[53] Subramanian P, Mazurenko I, Zaitsev V, Coffinier Y, Boukherroub R, Szunerits S. Diamond nanowires modified with poly[3-(pyrrolyl)carboxylic acid] for the immobilization of histidine-tagged peptides. Analyst 2014;139:4343-4349.

[54] Nebel CE, Yang N, Uetsuka H, Osawa E, Tokuda N, Williams A. Diamond nanowires, a new approach towards next generation electrochemical gene sensor platforms. Diam. Relat. Mater. 2009;18:910-917. 
[55] Yang Y, Oh J-W, Kim Y-R, Terashima C, Fujishima A, Kim JS, Kim H. Enhanced electrogenerated chemiluminescence of a ruthenium tris $\left(2,2^{\prime}\right)$ bipyridyl/tripropylamine system on a boron-doped diamond nanograss array. Chem. Commun. 2010;46:57935795.

[56] Yang N, Smirnov W, Nebel CE. Fabrication, properties and electrochemical applications of diamond nanostructures. MRS Proceedings 2013;1511:mrsf12-1511ee07-01.

[57] van Wyk VD, Baker PGL, Waryo T, Iwuoha EI, O'Sullivan C. Electrochemical evaluation of a novel boron doped diamond (BDD) material for application as potential electrochemical capacitor. Anal. Lett. 2011;44:2005-2018.

[58] Yu S, Yang N, Zhuang H, Meyer J, Mandal S, Williams OA, Lilge I, Schönherr H, Jiang X. Electrochemical supercapacitors from diamond. J. Phys. Chem. C. 2015;33:18918-18926.

[59] Honda K, Rao TN, Tryk DA, Fujishima A, Watanabe M, Yasui K, Masuda H. Electrochemical characterization of the nanoporous honeycomb diamond electrode as an electrical double-layer capacitor. J. Electrochem. Soc. 2000;147:659-664.

[60] Honda K, Rao TN, Tryk DA, Fujishima A, Watanabe M, Yasui K, Masuda H. Impedance characteristics of the nanoporous honeycomb diamond electrodes for electrical double-layer capacitor applications. J. Electrochem. Soc. 2001;148:A668A679.

[61] Yoshimura M, Honda K, Uchikado R, Kondo T, Rao TN, Tryk DA, Fujishima A, Sakamoto Y, Yasui K, Masuda H. Electrochemical characterization of nanoporous honeycomb diamond electrodes in non-aqueous electrolytes. Diam. Relat. Mater. 2001;10:620-626.

[62] Gao F, Wolfer M, Nebel CE. Highly porous diamond foam as a thin-film microsupercapacitor material. Carbon 2014;80:833-840.

[63] Kondo T, Lee S, Honda K, Kawai T. Conductive diamond hollow fiber membranes. Electrochem. Commun. 2009;11:1688-1691.

[64] Zhuang H, Yang N, Fu H, Zhang L, Wang C, Huang N, Jiang X. Diamond network: template-free fabrication and properties. ACS Appl. Mater. Interfaces 2015;7:53845390.

[65] Gao F, Lewes-Malandrakis G, Wolfer M, Müller-Sebert W, Gentile P, Aradilla D, Schubert T, Nebel CE. Diamond-coated silicon wires for supercapacitor applications in ionic liquids. Diam. Relat. Mater. 2015;51:1-6. 
[66] Gao F, Nebel CE. Diamond-based supercapacitors: realization and properties. ACS Applied Mater. Interface, 2015; doi: 10.1021/acsami.5b07027

[67] Almeida EC, Azevedo AF, Baldan MR, Braga NA, Rosolen JM, Ferreira NG. Nanocrystalline diamond/carbon felt as a novel composite for electrochemical storage energy in capacitor. Chem. Phys. Lett. 2007;438:47-52.

[68] Almeida EC, Baldan MR, Rosolen JM, Ferreira NG. Impedance characteristics of the diamond/carbon fiber electrodes for electrical double-layer capacitor. Diam. Relat. Mater. 2008;17:1529-1533.

[69] Siuzdak K, Bogdanowicz R, Sawczak M, Sobaszek M. Enhanced capacitance of composite $\mathrm{TiO}_{2}$ nanotube/boron-doped diamond electrodes studied by impedance spectroscopy. Nanoscale 2015;7:551-558.

[70] Gao F, Nebel CE. Diamond nanowire forest decorated with nickel hydroxide as a pseudocapacitive material for fast charging-discharging. phys. status solidi a, 2015; doi: 10.1002/pssa.201532131.

[71] Zanin H, May PW, Fermin DJ, Plana D, Vieira SMC, Milne WI, Corat EJ. Porous boron-doped diamond/carbon nanotube electrodes. ACS Appl. Mater. Interfaces 2014;6:990-995.

[72] Kondo T, Kodama Y, Ikezoe S, Yajima K, Aikawa T, Yuasa M. Porous boron-doped diamond electrodes fabricated via two-step thermal treatment. Carbon 2014;77:783789.

[73] Hebert C, Scorsone E, Mermoux M, Bergonzo P. Porous diamond with high electrochemical performance. Carbon 2015;90:102-109.

[74] Kato H, Hees J, Hoffmann R, Wolfer M, Yang N, Yamasaki S, Nebel CE. Diamond foam electrodes for electrochemical applications. Electrochem. Commun., 2013;33:8891.

[75] Gao F, Giese C, Lewes-Malandrakis G, Nebel CE. Porous diamond membrane fabricated by templated growth for electrochemical separation processes. 2015 ECS Meeting Abstract, 213-A.

[76] Ruffinatto S, Girard HA, Becher F, Arnault JC, Tromson D, Bergonzo P. Diamond porous membranes: A material toward analytical chemistry. Diam.Relat. Mater. 2015;55:123-130.

[77] Gao F, Thomann R, Nebel CE. Aligned Pt-diamond core-shell nanowires for electrochemical catalysis. Electrochem. Commun. 2015;50:32-35.

[78] Williams OA (ed.). Nanodiamond. RSC Publisher, 2014. 
[79] Novoselova IA, Fedoryshena EN, Panov EV, Bochechka AA, Romanko LA. Electrochemical properties of compacts of nano-and microdisperse diamond powders in aqueous electrolytes. Phys. Solid State 2004;46:748-750.

[80] Zang JB, Wang YH, Zhao SZ, Bian LY, Lu J. Electrochemical properties of nanodiamond powder electrodes. Diam. Relat. Mater. 2007;16:16-20.

[81] Holt KB. Undoped diamond nanoparticles: origins of surface redox chemistry. Phys. Chem. Chem. Phys. 2010;12:2048-2058.

[82] Scholz J, McQuillan AJ, Holt KB. Redox transformations at nanodiamond surfaces revealed by in situinfrared spectroscopy. Chem. Commu. 2011;47:12140-12142.

[83] Holt KB, Ziegler C, Zang J, Hu J, Foord JS. Scanning electrochemical microscopy studies of redox processes at undoped nanodiamond surfaces. J. Phys. Chem. C 2009;113:2761-2770.

[84] Holt KB, Caruana DJ, Millan-Barrios EJ. Electrochemistry of undoped diamond nanoparticles: accessing surface redox states. J. Am. Chem. Soc. 2009;131:1127211273.

[85] Holt KB, Ziegler C, Caruana DJ, Zang J, Millan-Barrios EJ, Hu J, Foord JS. Redox properties of undoped $5 \mathrm{~nm}$ diamond nanoparticles. Phys. Chem. Chem. Phys. 2008;10:303-310

[86] Varley ATS, Hirani M, Harrison G, Holt KB. Nanodiamond surface redox chemistry: influence of physicochemical properties on catalytic processes. Faraday Discuss. 2014;172:349-364.

[87] Zang J, Wang Y, Bian L, Zhang J, Meng F, Zhao Y, Ren S, Qu X. Surface modification and electrochemical behaviour of undoped nanodiamonds. Electrochim. Acta 2012;72:68-73.

[88] Wang Y, Huang H, Zang J, Meng F, Dong L, Su J. Electrochemical behavior of fluorinated and aminated nanodiamond. Int. J. Electrochem. Sci. 2012;7:6807-6815.

[89] Hongthani W, Fermin DJ. Layer-by-layer assembly and redox properties of undoped HPHT diamond particles. Diam. Relat. Mater. 2010;19:680-684.

[90] Plana D, Humphrey JJL, Bradley KA, Celorrio V, Fermin DJ. Charge transport across high surface area metal/diamond nanostructured composites. ACS Appl. Mater. Interfaces 2013;5:2985-2990.

[91] Hongthani, W; Fox NA, Fermin DJ. Electrochemical properties of two dimensional assemblies of insulating diamond particles. Langmuir 2011;27:5112-5118. 
[92] Plana D, Humphrey JJL, Bradley KA, Celorrio V, Fermin DJ. Charge transport scross high durface srea metal/diamond nanostructured composites. ACS Appl. Mater. Interfaces 2013;5:2985-2990.

[93] Shahrokhian S, Ghalkhani M. Glassy carbon electrodes modified with a film of nanodiamond-graphite/chitosan: Application to the highly sensitive electrochemical determination of azathioprine. Electrochim. Acta 2010;55:3621-3627.

[94] Shahrokhian S, Khafaji M. Application of pyrolytic graphite modified with nanodiamond/graphite film for simultaneous voltammetric determination of epinephrine and uric acid in the presence of ascorbic acid. Electrochim. Acta 2010;55:9090-9096.

[95] Chen LH, Zang JB, Wang YH, Bian LY. Electrochemical oxidation of nitrite on nanodiamond powder electrode. Electrochim. Acta 2008;53:3442-3445.

[96] Shahrokhian S, Bayat M. Pyrolytic graphite electrode modified with a thin film of a graphite/diamond nano-mixture for highly sensitive voltammetric determination of tryptophan and 5-hydroxytryptophan. Microchim. Acta 2011;174:361-366.

[97] Shahrokhian S, Nassab NH. Nanodiamond decorated with silver nanoparticles as a sensitive film modifier in a jeweled electrochemical sensor: application to voltammetric determination of thioridazine. Electroanalysis 2013;25:417-425.

[98] Habibi B, Jahanbakhshi M. Sensitive determination of hydrogen peroxide based on a novel nonenzymatic electrochemical sensor: silver nanoparticles decorated on nanodiamonds. J. Iran. Chem. Soc. 2015;12:1431-1438.

[99] Bian LY, Wang YH, Lu J, Zang JB. Synthesis and electrochemical properties of $\mathrm{TiO}_{2} /$ nanodiamond nanocomposite. Diam. Relat. Mater. 2010;19:1178-1182.

[100] Zhao W, Xu JJ, Qiu QQ, Chen HY. Nanocrystalline diamond modified gold electrode for glucose biosensing. Biosens. Bioelectron. 2006;22:649-655.

[101] Briones M, Casero E, Petit-Dominguez MD, Ruiz MA, Parra-Alfambra AM, Pariente F, Lorenzo E, Vazquez L. Diamond nanoparticles based biosensors for efficient glucose and lactate determination. Biosens. Bioelectron. 2015;68:521-528.

[102] Gopalan AI, Lee K-P, Komathi S. Bioelectrocatalytic determination of nitrite ions based on polyaniline grafted nanodiamond. Biosens. Bioelectron. 2010;26:1638-1643.

[103] Zhu J-T, Shi C-G, Xu J-J, Chen H-Y. Direct electrochemistry and electrocatalysis of hemoglobin on undoped nanocrystalline diamond modified glassy carbon electrode. Bioelectrochemistry 2007;71:243-248. 
[104] Gopalan AI, Komathi S, Sai Anand G, Lee KP. Nanodiamond based sponges with entrapped enzyme: a novel electrochemical probe for hydrogen peroxide. Biosens. Bioelectron. 2013;46:136-141.

[105] Nicolau E, Mendez J, Fonseca JJ, Griebenow K, Cabrera CR. Bioelectrochemistry of non-covalent immobilized alcohol dehydrogenase on oxidized diamond nanoparticles. Bioelectrochemistry 2012;85:1-6.

[106] Briones M, Casero E, Petit-Dominguez MD, Ruiz MA, Parra-Alfambra AM, Pariente F, Lorenzo E, Vazquez L. Diamond nanoparticles based biosensors for efficient glucose and lactate determination. Biosens. Bioelectron. 2015;68:521-528.

[107] Zhang WL, Patel K, Schexnider A, Banu S, Radadia AD. Nanostructuring of biosensing electrodes with nanodiamonds for antibody immobilization. ACS Nano 2014;8:1419-1428.

[108] Bian LY, Wang YH, Zang JB, Meng FW, Zhao YL. Detonation-synthesized nanodiamond as a stable support of Pt electrocatalyst for methanol electrooxidation. Int. J. Electrochem. Sci. 2012;7:7295-7303.

[109] Bian L, Wang Y, Zang J, Yu J, Huang H. Electrodeposition of Pt nanoparticles on undoped nanodiamond powder for methanol oxidation electrocatalysts. J. Electroanal. Chem. 2010;644:85-88.

[110] Celorrio V, Plana D, Florez-Montano J, Montes de Oca MJ, Moore A, Lazaro MJ, Pastor E, Fermin DJ. Methanol oxidation at diamond-supported Pt nanoparticles: effect of the diamond surface termination. J. Phys. Chem. C 2013;117:21735-21742.

[111] Zang J, Wang Y, Bian L, Zhang J, Meng F, Zhao Y, Lu R, Qu X, Ren S. Graphene growth on nanodiamond as a support for a Pt electrocatalyst in methanol electrooxidation. Carbon 2012;50:3032-3038.

[112] Zang J, Wang Y, Bian L, Zhang J, Meng F, Zhao Y, Qu X, Ren S. Bucky diamond produced by annealing nanodiamond as a support of Pt electrocatalyst for methanol electrooxidation. Int. J. hydrogen Energy, 2012;37:6349-6355.

[113] $\mathrm{Hu}$ J, Lu X, Foord JS. Nanodiamond pretreatment for the modification of diamond electrodes by platinum nanoparticles. Electrochem. Comm. 2010;12:676-679.

[114] La-Torre-Riveros L, Guzman-Blas R, Mendez-Torres AE, Prelas M, Tryk DA, Cabrera CR. Diamond nanoparticles as a support for Pt and PtRu catalysts for direct methanol fuel cells. ACS Applied Mater. Interface 2012;4:1134-1147.

[115] Levashov EA, Vakaev PV, Zamulaeva EI, Kudryashov AE, Kurbatkina VV, Shtansky DV, Voevodin AA, Sanz A. Disperse-strengthening by nanoparticles advanced 
tribological coatings and electrode materials for their deposition. Surf. Coat. Technol. 2007;201:6176-6181

[116] Tsai L-N, Shen G-R, Cheng Y-T, Hsu W. Performance improvement of an electrothermal microactuator fabricated using Ni-diamond nanocomposite. J. Microelectromech. Syst. 2006;15:149-158.

[117] Wang Y, Zhao Y, Lu R, Dong L, Zang J, Lu J, Xu X. Nano titania modified nanodiamonds as stable electrocatalyst supports for direct methanol fuel cells. J. Electrochem. Soc. 2015;162:F211-F215.

[118] Moore A, Celorrio V, de Oca MM, Plana D, Hongthani W, Lazaro MJ, Fermin DJ. Insulating diamond particles as substrate for Pd electrocatalysts. Chem. Commun. 2011;47:7656-7658.

[119] Wang Y, Zang J, Dong L, Pan H, Yuan Y, Wang Y. Graphitized nanodiamond supporting PtNi alloy as stable anodic and cathodic electrocatalysts for direct methanol fuel cell. Electrochim. Acta 2013;113:583-590.

[120] Lu X, Hu J-P, Foord JS, Wang Q. Electrochemical deposition of Pt-Ru on diamond electrodes for the electrooxidation of methanol. J. Electroanal. Chem. 2011;654:38-43.

[121] La-Torre-Riveros L, Guzman-Blas R, Mendez-Torres AE, Prelas M, Tryk DA, Cabrera CR. Diamond nanoparticles as a support for Pt and Pt-Ru catalysts for direct methanol fuel cells. ACS Appl. Mater. Interfaces 2012;4:1134-1147.

[122] La-Torre-Riveros L, Abel-Tatis E, Mendez-Torres AE, Tryk DA, Prelas M, Cabrera CR. Synthesis of platinum and platinum-ruthenium-modified diamond nanoparticles. J. Nanopart. Res. 2011;13:2997-3009.

[123] Lu R, Zang J, Wang Y, Zhao Y. Microwave synthesis and properties of nanodiamond supported $\mathrm{PtRu}$ electrocatalyst for methanol oxidation. Electrochim. Acta 2012;60:329-333.

[124] Fujimura T, Dolmatov VY, Burkat GK, Orlova EA, Veretennikova MV. Electrochemical codeposition of Sn-Pb-metal alloy along with detonation synthesis nanodiamonds. Diam. Relat. Mater. 2004;13:2226-2229.

[125] Salazar-Banda GR, Eguiluz KIB, Avaca LA. Boron-doped diamond powder as catalyst support for fuel cell applications. Electrochem. Commun. 2006;9:59-64.

[126] Bian LY, Wang YH, Lu J, Zang JB. Synthesis and electrochemical properties of $\mathrm{TiO}_{2} /$ nanodiamond nanocomposite. Diam. Relat. Mater. 2010;19:1178-1182. 
[127] Zhao Y, Wang Y, Dong L, Huang J, Zang J, Lu J, Xu X. Core-shell structural nanodiamond@TiN supported Pt nanoparticles as a highly efficient and stable electrocatalyst for direct methanol fuel cells. Electrochim. Acta 2014;148:8-14.

[128] Bian LY, Wang YH, Zang JB, Meng FW, Zhao YL. Microwave synthesis and characterization of Pt nanoparticles supported on undoped nanodiamond for methanol electrooxidation. Int. J. hydrogen Energy 2012;37:1220-1225.

[129] Portet C, Yushin G, Gogotsi Y. Electrochemical performance of carbon onions, nanodiamonds, carbon black and multiwalled nanotubes in electrical double layer capacitors. Carbon 2007;45:2511-2518.

[130] Sun YQ, Wu Q, Xu YX, Bai H, Li C, Shi GG. Highly conductive and flexible mesoporous graphitic films prepared by graphitizing the composites of graphene oxide and nanodiamond. J. Mater. Chem. 2011;21:7154-7160.

[131] Bushueva EG, Galkin PS, Okotrub AV, Bulusheva LG, Gavrilov NN, Kuznetsov VL, Moiseekov SI. Double layer supercapacitor properties of onion-like carbon materials. phys. stat. sol. (b) 2008;245:2296-2299.

[132] Portet C, Chmiola J, Gogotsi Y, Park S, Lian K. Electrochemical characterizations of carbon nanomaterials by the cavity microelectrode technique. Electrochim. Acta 2008;53:7675-7680.

[133] Sun YQ, Wu Q, Xu YX, Bai H, Li C, Shi GG. Highly conductive and flexible mesoporous graphitic films prepared by graphitizing the composites of graphene oxide and nanodiamond. J. Mater. Chem. 2011;21:7154-7160.

[134] Park S, Lian K, Gogotsi Y. Pseudocapacitive behavior of carbon nanoparticles modified by phosphomolybdic acid. J. Electrochem. Soc. 2009;156:A921-A926.

[135] Zang J, Wang Y, Zhao X, Xin G, Sun S, Qu X, Ren S. Electrochemical synthesis of polyaniline on nanodiamond powder. Int. J. Electrochem. Sci. 2012;7:1677-1687.

[136] Kovalenko I, Bucknall DG, Yushin G. Detonation nanodiamond and onion-likecarbon-embedded polyaniline for supercapacitors. Adv. Func. Mater. 2010;20:39793986.

[137] Wang Q, Plylahan N, Shelke MV, Devarapalli RR, Li M, Subramanian P, Djenizian T, Boukherroub R, Szunerits S. Nanodiamond particles/reduced graphene oxide composites as efficient supercapacitor electrodes. Carbon, 2014;68:175-184.

[138] Kausar A, Ashraf R, Siddiq M. Polymer/nanodiamond composites in Li-ion batteries: a review. Polymer-Plast Technol. 2014;53:550-563. 
[139] Gu W, Peters N, Yushin G. Functionalized carbon onions, detonation nanodiamond and mesoporous carbon as cathodes in li-ion electrochemical energy storage devices. Carbon 2013;53:292-301.

[140] Tamburri E, Orlanducci S, Guglielmotti V, Reina G, Rossi M, Terranova ML. Engineering detonation nanodiamond - polyaniline composites by electrochemical routes: Structural features and functional characterizations. Polymer 2011;52:50015008.

[141] Gomez H, Ram MK, Alvi F, Stefanakos E, Kumar A, Novel synthesis, characterization, and corrosion inhibition properties of nanodiamond-polyaniline films. J. Phys. Chem. C 2010;114:18797-18804.

[142] Zhao Z, Dai Y. Nanodiamond/carbon nitride hybrid nanoarchitecture as an efficient metal-free catalyst for oxidant- and steam-free dehydrogenation. J. Mater. Chem. A 2014;2:13442-13451.

[143] Fischer AE, Swain GM. Preparation and characterization of boron-doped diamond powder: a possible dimensionally stable electrocatalyst support material. J. Electrochem. Soc. 2005;152:B369-B375.

[144] Swope AAVM, Swain GM. The physicochemical and electrochemical properties of 100 and $500 \mathrm{~nm}$ diameter diamond powders coated with boron-doped nanocrystalline diamond. J. Electrochem. Soc. 2005;155:B1013-B1022.

[145] Zang J, Wang Y, Huang H, Tang W. Electrochemical behavior of high-pressure synthetic boron doped diamond powder electrodes. Electrochim. Acta 2007;52:43984402.

[146] Cunci L, Cabrera CR. Preparation and electrochemistry of boron-doped diamond nanoparticles on glassy carbon electrodes. Electrochem. Solid-State Lett. 2011;14:K17-K19.

[147] Heyer S, Janssen W, Turner S, Lu Y-G, Yeap WS, Verbeeck J, Haenen K, Krueger A. Toward deep blue nano hope diamonds: heavily boron-doped diamond nanoparticles. ACS Nano 2014;8:5757-5764.

[148] Swope AAVM, Swain GM. The physicochemical and electrochemical properties of 100 and $500 \mathrm{~nm}$ diameter diamond powders coated with boron-doped nanocrystalline diamond. J. Electrochem. Soc. 2005;155:B1013-B1022.

[149] Salazar-Banda GR, Eguiluz KIB, Avaca LA. Boron-doped diamond powder as catalyst support for fuel cell applications. Electrochem. Comm. 2007;9:59-64. 
[150] Ko CY, Huang JH, Raina S, Kang WP. A high performance non-enzymatic glucose sensor based on nickel hydroxide modified nitrogen-incorporated nanodiamonds. Analyst 2013;138:3201-3208.

[151] Spătaru N, Zhang X, Spătaru T, Tryk DA, Fujishima A. Anodic deposition of $\mathrm{RuO}_{\mathrm{x}} \cdot \mathrm{nH}_{2} \mathrm{O}$ at conductive diamond films and conductive diamond powder for electrochemical capacitors. J. Electrochem. Soc. 2008;155:D73-D77.

[152] Lee SK, Song MJ, Kim JH, Kan TS, Lim YK, Ahn JP, Lim DS. 3D-networked carbon nanotube/diamond core-shell nanowires for enhanced electrochemical performance. NPG Asia Mater. 2014;6:e115.

[153] Muna GW, Swope VM, Swain GM, Poeter MD. Electrochemically modulated liquid chromatography using a boron-deped particle stationary phase. J. Chromatogr. A 2008;1210:154-159.

[154] Hees J, Hoffmann R, Kriele A, Smirnov W, Obloh H, Glorer K, Raynor B, Driad R, Yang N, Williams OA, Nebel CE. Nanocrystalline diamond nanoelectrode arrays and ensembles. Acs Nano 2011;5:339-3346.

[155] Hees J, Hoffmann R, Yang N, Nebel CE. Diamond nanoelectrode arrays for the detection of surface sensitive adsorption. Chem. Euro.J. 2013;19:11287-11292.

[156] Arrigan DWM. Nanoelectrodes, nanoelectrode arrays and their applications. Analyst 2004;129:1157-1165.

[157] Compton RG, Wildgoose GG, Rees NV, Streeter I, Baron R, Design, fabrication, characterisation and application of nanoelectrode arrays. Chem. Phys. Lett. 2008;459:1-17.

[157] Murray RW. Nanoelectrochemistry: metal nanoparticles, nanoelectrodes, and nanopores. Chem. Rev. 2008;108:2688-2720.

[159] Wadhawan JD, Compton RG. Electrochemistry (Vol. 12), RSC Publisher, 2013.

[160] Mirkin MV, Amemiya S. Nanoelectrochemistry, CRC Press, 2015.

[161] Smirnov W, Yang N, Hoffmann R, Hees J, Obloh H, Müller-Sebert W, Nebel CE. Integrated all-diamond ultramicroelectrode arrays: optimization of Faradaic and capacitive currents. Anal. Chem., 2011;83:7438-7443.

[162] Yang N, Smirnov W, Hees J, Hoffmann R, Kriele A, Obloh H, Müller-Sebert W, Nebel CE. Diamond ultramicroelectrode arrays for achieving maximum Faradaic current with minimum capacitive charging. physica status solidi (a), 2011;208:20872092. 
[163] Guo J, Lindner E. Cyclic voltammograms at coplanar and shallow recessed microdisk electrode arrays: guidelines for design and experiment. Anal. Chem. 2009;81:130-138.

[164] Fleischmann M, Pons S, Daschbach J. The ac impedance of spherical, cylindrical, disk, and ring microelectrodes. J. Electroanal. Chem. 1991;317:1-26.

[165] Fleischmann M, Pons S. The behavior of microdisk and microring electrodes. Mass transport to the disk in the unsteady state: the ac response. J. Electroanal. Chem. 1988;250:277-283.

[166] Dincer C, Laubender E, Hees J, Nebel CE, Urban G, Heinze J. SECM detection of single boron doped diamond nanodes and nanoelectrode arrays using phase-operated shear force technique. Electrochem. Commun. 2012;24:123-127.

[167] Hamers RJ. Nanotechnology: diamonds are for tethers. Nature 2008;454:708-709. 


\section{Bio}

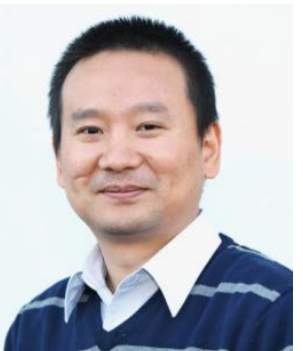

Dr. Nianjun Yang is a senior scientist and the group leader of nanomaterials at Institute of Materials Engineering, University of Siegen, Germany. His current research interests cover carbon electrochemistry and interface as well as carbon based electrochemical devices. In these fields, he has published 84 peer reviewed journal papers, edited 2 books, and contributed 7 book chapters. He is the editor of book series of „Nanocarbon Chemistry and Interface“ (wiley) and the guest-editor for physica status solidi (a), Electroanalysis, Journal Electroanalytical Chemistry, Diamond and Related Materials, ACS Applied Materials and Interface. He is the organizer and the program committee member of several diamond and carbon related international conferences.

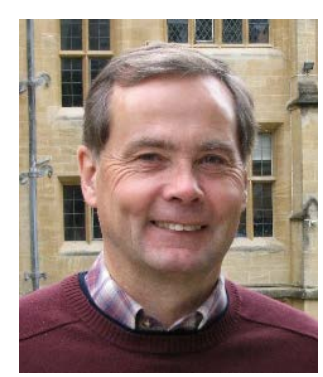

Prof. John. S. Foord obtained his PhD from King's College at the University of Cambridge. He was a GA Selwyn Centenary Research Fellow in Selwyn College, Cambridge, Lecturer at University of Southampton and Oxford, and became a Professor of Chemistry at Univeristy of Oxford in 1998. He has been awarded the Meldola Medal of the Royal Society of Chemistry, and is a Fellow of the Royal Society of Chemistry. His group is concerned with the chemical synthesis of new solid-state nanomaterials, to enable novel applications, along with closely related studies on the surface chemistry of materials. He has published over 300 refereed papers, and is a long-standing member of the program committees of the European Diamond Conference and the Hasselt Diamond Workshop, as well as being a previous organiser of symposia at EMRS.

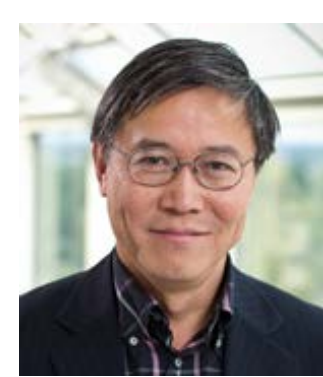

Dr. Xin Jiang is a professor and holder of the Chair of Surface and Materials Technology at University of Siegen since 2003. He received the award "State Specially Recruited Expert" of China in 2013. He was a Changjiang-Visiting Chair Professor at Dalian University and Science and Technology, China. His habilitation and PhD degree were conducted in 1998 at Technical University of Braunschweig, Germany and in 1990 at the Technical University of Aachen (RWTH), Germany, respectively. His current research fields cover the growth and applications of thin films, nanomaterials as well as materials characterization. He has published 228 peer reviewed journal papers, and contributed 8 book and book chapters. He has delivered numerous invited talks/lectures at international conferences. 